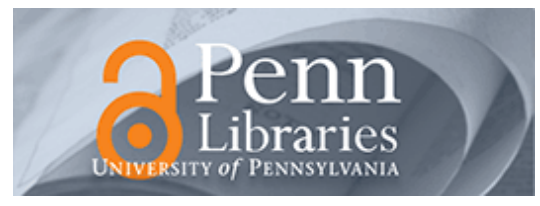

University of Pennsylvania

ScholarlyCommons

Finance Papers

Wharton Faculty Research

2002

\title{
Leaning for the Tape: Evidence of Gaming Behavior in Equity Mutual Funds
}

Mark M. Carhart

Ron Kaniel

David K. Musto

University of Pennsylvania

Adam V. Reed

Follow this and additional works at: https://repository.upenn.edu/fnce_papers

Part of the Finance Commons, and the Finance and Financial Management Commons

\section{Recommended Citation}

Carhart, M. M., Kaniel, R., Musto, D. K., \& Reed, A. V. (2002). Leaning for the Tape: Evidence of Gaming Behavior in Equity Mutual Funds. The Journal of Finance, 57 (2), 661-693. http://dx.doi.org/10.1111/ 1540-6261.00438

This paper is posted at ScholarlyCommons. https://repository.upenn.edu/fnce_papers/277

For more information, please contact repository@pobox.upenn.edu. 


\title{
Leaning for the Tape: Evidence of Gaming Behavior in Equity Mutual Funds
}

\author{
Abstract \\ We present evidence that fund managers inflate quarter-end portfolio prices with last-minute purchases \\ of stocks already held. The magnitude of price inflation ranges from 0.5 percent per year for large-cap \\ funds to well over 2 percent for small-cap funds. We find that the cross section of inflation matches the \\ cross section of incentives from the flow/performance relation, that a surge of trading in the quarter's last \\ minutes coincides with a surge in equity prices, and that the inflation is greatest for the stocks held by \\ funds with the most incentive to inflate, controlling for the stocks' size and performance. \\ Disciplines \\ Finance | Finance and Financial Management
}




\section{Leaning for the Tape: Evidence of Gaming Behavior In Equity Mutual Funds*}

\author{
Mark M. Carhart \\ Goldman Sachs Asset Management \\ 32 Old Slip, $24^{\text {th }}$ Floor \\ New York, NY 10005 \\ (212) 357-5993 \\ mark.carhart@gs.com \\ David K. Musto \\ Wharton School, Finance Dept. \\ 3620 Locust Walk \\ Philadelphia, PA 19104-6367 \\ (215) 898-4239 \\ musto@wharton.upenn.edu
}

\author{
Ron Kaniel \\ University of Texas at Austin \\ Graduate School of Business \\ Austin, TX 78712 \\ (512) 471-5781 \\ ron.kaniel@bus.utexas.edu \\ Adam V. Reed \\ Wharton School, Finance Dept. \\ 3620 Locust Walk \\ Philadelphia, PA 19104-6367 \\ (215) 898-1588 \\ adam22@wharton.upenn.edu
}

This Revision October 23, 2000

*Correspondence to David Musto, musto@,wharton.upenn.edu, FAX (215) 898-6200.

The authors thank Marshall Blume, Susan Christoffersen, Dan Deli, Diane Del Guercio, Roger Edelen, Chris Geczy, Bruce Grundy, Don Keim, Alan Lee, Andrew Metrick, Rob Stambaugh, Laura Starks, Paula Tkac, Kent Womack, Jason Zweig and seminar participants at the Securities Exchange Commission, Iowa, Texas and the Wharton School, participants in the Western Finance Association meeting in Sun Valley, Idaho and the Academic/Practitioners Conference on Mutual Funds at the Investment Company Institute, René Stulz and an anonymous referee for helpful comments and suggestions. Financial and other support from the Rodney L. White Center for Financial Research and the Wharton Financial Institutions Center is gratefully acknowledged. The views expressed are those of the authors alone, and do not necessarily reflect the views of Goldman Sachs Asset Management, or Wharton or UT for that matter. 


\title{
Leaning for the Tape: Evidence of Gaming Behavior In Equity Mutual Funds
}

\begin{abstract}
We show that quarter-end prices of equity funds are inflated, presenting a large profit opportunity to potential sellers and an equivalent hazard to buyers and remaining shareholders. The magnitude of price inflation ranges from 50 basis points per year for large-cap funds to well over 200 basis points for small-cap funds. Evidence suggests that fund managers cause the inflation with last-minute purchases of stocks already held, deliberately moving performance to one period from the next. We find that the cross section of inflation matches the cross section of incentives from the flow/performance relation, that a surge of trading in the quarter's last minutes coincides with a surge in equity prices, and that the inflation is greatest for the stocks held by the funds with most incentive to inflate, controlling for the stocks' size and performance.
\end{abstract}


Quarter-end and especially year-end equity mutual fund prices are abnormally high. We present strong evidence that some mutual fund managers mark up their holdings at quarter end through aggressive trading of stocks they already hold. Funds with the greatest ability and most incentive to improve their performance exhibit the largest turn-of-quarter effect. Intradaily data show a surge of transactions and transaction prices in the quarter's last few minutes, and fund-holdings data show a larger effect in the funds with the most incentive to mark up. Considering that open-end equity funds intermediate $\$ 3.46$ trillion (year-end 1999), ${ }^{1}$ this turn-of-quarter inflation of their prices is a significant opportunity for potential sellers, and significant hazard for everybody else.

In general, open-end domestic equity mutual funds calculate their net asset values per share (NAVs) from the closing transaction prices of their holdings. While there are obvious benefits from pricing off of the most recent arms-length transactions, there are potential concerns as well. One of these, explored by Chalmers, Edelen and Kadlec (2000), Boudoukh et al. (2000) and others, is the age of thinly-traded stocks' last trades, which allows speculators to profit off longer-term shareholders. The concern we explore here is the influence of last-minute trading on last-trade prices, which allows fund managers to move performance between periods with last-minute trading in stocks they already hold, a practice alternately known as "painting the tape" or "marking up." Market regulators regard this practice as illegal. ${ }^{2}$

If managers mark up to move performance to one period from the next, the result is abnormally high NAVs at period ends. Because of the significance of quarterly and

\footnotetext{
1 Investment Company Institute Mutual Fund Fact Book, 2000 Edition, p. 73. This figure excludes international funds.

2 See, e.g., "Putting A False Face on Fund Performance?" Washington Post, January 9, 2000, p. H01.
} 
annual performance figures, the ends of calendar quarters — particularly the fourth—are logical targets. We first establish that quarter-end distortion of NAVs is economically and statistically significant, then study fund returns, portfolio holdings, stock returns, and stock trades to determine whether the marking-up tactic is responsible.

We first establish the abnormal-NAV pattern around quarter ends. Equity fund returns, net of the S\&P 500, are abnormally high on the last day of the quarter, especially the fourth, and abnormally low the next day. This effect appears in both our database of daily fund returns and in the Lipper daily fund indices. Magnitudes range from around 50 basis points per year for large-cap funds to well over 200 basis points for small-cap funds. There is little or no effect at month-ends that are not quarter-ends.

We then focus in on the cause of the abnormal returns with a sequence of tests on the cross section of fund and stock returns. We confirm the link between the quarter-end rise and the next-day decline by showing that larger increases precede larger decreases in the cross section, which is not the case for fund returns on other days.

Next, to establish whether mutual-fund managers are actively involved, we check if funds with relatively more incentive to mark up do in fact show more marking up. We test two hypotheses. First, funds just below the S\&P 500 for the year mark up to beat the index (Zweig (1997)), which we call "benchmark-beating." Second, funds with the best performance mark up to improve their year-end ranking and to profit from the convexity of the flow/performance relation (Ippolito (1992), Sirri and Tufano (1998)) and managerial incentive pay. We denote this as the "leaning-for-the-tape" hypothesis.

Despite its intuitive appeal, we reject the benchmark-beating hypothesis. As Degeorge, Patel and Zeckhauser (1999) observe, manipulation of a statistic to beat a 
benchmark should distort the empirical distribution of the statistic around the benchmark. In the empirical distribution of funds' calendar-year returns there is no distortion around the S\&P return, such as Degeorge et al. (1999) find in corporate-earnings numbers around analysts' expectations, and no distortion around zero return.

However, we find significant evidence for the leaning-for-the-tape hypothesis. We find that the year's best-performing funds have the largest abnormal year-end return reversals, and the quarter's best-performing funds have the largest abnormal quarter-end return reversals. Intraday data isolate much of the pattern in a small window of trading time around the quarter-end day's close. Finally, we find that the stocks in the disclosed portfolios of the best-performing funds, controlling for capitalization and recent return, show significantly more price-inflation at year-end than do other stocks. We conclude that marking-up by mutual funds explains some, if not all, of the price inflation.

The rest of the paper is in five sections. Section I covers the relevant literature on equity and equity-fund returns and Section II tests for NAV-inflation at period-ends. Section III presents evidence from the cross section of fund returns. Section IV tests for marking up on transactions data, and Section V summarizes and concludes.

\section{Background and Literature}

Two literatures relate to regularities in equity-fund returns: the extensive literature on equity-return seasonality, and the more recent literature on equity-fund-return seasonality, which is qualitatively different in both causes and implications. We cover each briefly, then describe the main hypotheses of this paper in the context of the 
literature on equity-fund agency issues, particularly those relating to the effect of fund performance on net cash flows.

\section{A Literature on Equity Return Seasonality}

The finance literature has uncovered and analyzed many peculiarities in equity returns in the days around the year end. Most attention has focused on small-cap issues. Relative to big-cap stocks, small-cap stocks shift significantly upward on each of the five trading days starting with the last of the year (Keim (1983), Roll (1983)) with a persistence across years that defies risk-based explanations. Explanations include tax-loss selling and window dressing. Tax-loss selling implies that retail investors' demand for stocks with poor past performance shifts up after the year-end tax deadline (see, e.g., Roll (1983), Ritter (1988)). Similarly, window dressing implies that institutional demand shifts up after year-end portfolio disclosures (e.g. Haugen and Lakonishok (1988), Musto (1997)). Neither explains why the shift starts a day before the year-end. ${ }^{3}$

Lining up daily index returns from 1963 to 1981 around month ends, Ariel (1987) isolates all of equities' positive average returns in the nine trading days starting with the last of the month. Various explanations are considered and discarded. Sias and Starks (1997) find that greater institutional ownership is associated with relatively better returns in the last four days of the year, and relatively worse in the first four days of the year and conclude that individual-investor tax-loss selling explains their finding. However, the average returns are virtually the same over these two periods, so they conclude it is

\footnotetext{
3 US mutual funds (with a few exceptions) use trade date +1 positions in calculating their daily NAV. Therefore, any changes in position that occur through trading on the last day of the year are not reflected in that day's NAV, but rather in the next day's NAV. However, US GAAP requires that semi-annual mutual fund reports reflect trade date positions, so these trades would be observed in the financial statements of funds with calendar fiscal years.
} 
actually the unusually poor performance of low institutional ownership stocks at the end of the year that drives their results.

At the intra-day frequency, Harris (1989) shows that transaction prices systematically rise at the close, and that this "day-end" anomaly is largest at month-ends (the study did not consider quarter- or year-ends separately) and when the last transaction is very near to the close in time. Harris also finds that the effect is stronger for lowpriced firms, and that buyers more frequently initiate day-end transactions.

The literature also documents price shifts directly traceable to institutional money management. Harris and Gurel (1986) show that prices on new constituents of the S\&P 500 index abnormally increase more than three percent upon announcement, all of which is eliminated within two weeks. Lynch and Mendenhall (1997), studying a period when S\&P additions and deletions were announced several trading days in advance, show transaction prices to be temporarily low on deletion days and high on addition days, and Reed (2000) confirms this for Russell 2000 additions and deletions. This effect is understood to be caused by the rebalancing trades of index managers.

\section{B $\quad$ Literature on Equity-Fund Return Seasonality}

It might seem redundant to measure the seasonality of equity-fund returns, because we might expect to see only the previously-discussed equity-return patterns. But the return on an equity fund is fundamentally different from the return on an equity, and the significance of this difference is only recently being addressed in the literature.

An equity return represents the difference between the prices of two arms-length transactions. It tells us what an investor would have earned if he bought at the initial 
price and sold at the later price. We can not know how much, if any, another investor could have transacted at these prices, as they are specific to the size and direction, and possibly other circumstances, of those two trades. In many cases, we abstract from transaction times, which is a minor concern for heavily-traded stocks but not for the sparsely-traded ones. An alternative is to look instead at bid and ask prices, but these, too, are only relevant for trades of a specific size.

An equity-fund return represents the difference between two NAV calculations, where each NAV is calculated from the closing prices of the fund's holdings on their respective primary exchanges. In contrast to an equity price, the NAV is the actual transaction price used for purchases and redemptions of fund shares that day. However, it is unlikely that an investor could purchase or sell all of the fund's equity positions at the closing prices used to calculate NAV. So NAVs directly represent the experience of hypothetical investors, without the guesswork and error, but they can depart from the “equilibrium” value of fund shares whenever equities' closing prices depart from their equilibrium values. When this departure is predictable, investors have a trading rule whose profits derive from the funds' other shareholders.

Some recent studies illustrate the predictability caused by nonsynchronous trading. Nonsynchroneity is most extreme in funds holding non-US equities that price these holdings using closing trades on their home exchange, yet allow fund purchases and redemptions up to the close of US trading (Goetzmann, Ivkovic and Rouwenhorst (2000)). But even purely domestic funds allow arbitrage to the extent they hold equities whose last trades tend to precede the market close (Chalmers, Edelen and Kadlec (2000), Boudoukh, et. al. (2000), Greene and Hodges (2000), etc.). These profit opportunities are 
sporadic and require good estimates of the magnitude of market moves between non-US and US market closes for international funds, or shortly before the US close for funds holding illiquid stocks.

In the popular press, Zweig (1997) demonstrates year-end seasonality in equity funds, and offers an explanation. From 1985 to 1995, the average equity fund outperformed the S\&P 500 by $53 \mathrm{bp}$ (bp=basis points, $1 / 100$ of $1 \%$ ) on the year's last trading day, and underperformed by $37 \mathrm{bp}$ on the next year's first trading day. Small-cap funds shifted more: 103bp above the S\&P, then 60bp below. This does not match the price shifts of small-cap equity indices, which generally beat the market on both days in those years. The explanation offered is that some fund managers cause the pattern by manipulating year-end valuations to improve their fund's return.

In SEC terminology, "marking the close" is "the practice of attempting to influence the closing price of a stock by executing purchase or sale orders at or near the close of the market". ${ }^{4}$ Zweig (1997) proposes that the fund managers just short of the S\&P 500 on the year's penultimate trading day try to pass it by marking the last day's close with buys. At the least, they could simply increase the probability their holdings close at the ask, but with more aggressive purchases, they could push up both the bid and the ask. Either way, this "marking up" would result in inflated NAVs and thereby inflated returns for holding periods ending on that date, and correspondingly deflated returns over periods beginning then.

\section{Two Models of the Marking-Up Strategy}

${ }^{4}$ SEC release \#36556, December 6, 1995. 
We consider two models, not mutually exclusive, of the marking-up strategy. The first is the scenario just described in which managers mark up to beat the S\&P, which we label the "benchmark-beating" model. The idea that funds mark up to beat the S\&P 500 has intuitive appeal; a fund's success at beating the S\&P 500 is a popular topic in the financial press and in prospectuses and annual reports, so it would seem that investors would reward it with new investment. Interestingly, however, they don't. A recent comparative study of the flow/performance relation in the mutual fund and pension fund industries, Del Guercio and Tkac (2000), finds new investment increases with performance in both segments, but beating the S\&P 500 brings significant new investment only to pension funds, not to mutual funds. So if a reward mechanism encourages marking up to beat the $\mathrm{S} \& \mathrm{P} 500$, it is probably something other than expectations of new investment. For example, managers' bonus plans might reward outperforming the S\&P 500.

The second model is suggested by the convex relation between past performance and subsequent net fund flows. As Ippolito (1992) and Sirri and Tufano (1998) show, net flows are much more sensitive to the difference between two high returns than between two lower returns, so that fund managers get more benefit from rank improvements if they are near the top of the distribution. This further implies that on the last day of a reference period, fund managers get more benefit from moving performance to that period from the next if their period-to-date performances are near the top of the distribution. They are in the high-slope region of the relation for this period and not particularly likely to be there for the next (Hendricks, Patel and Zeckhauser (1993), Brown and Goetzmann (1995), Carhart (1997)), which increases their incentive to move 
performance from the next reference period. Marking-up at period end moves performance from the next period. So in the second model, which we label the "leaningfor-the-tape" model (picture runners at the finish line), funds mark up at the end of a reference period to improve a superior performance.

The primary reference period would intuitively be the calendar year. Returns over calendar years figure disproportionately in the analysis of fund performance in the press, in mutual-fund ratings and databases, and in the academic literature. And managers' bonus plans are typically described as calendar-year based. Calendar quarters would be a secondary target, given their prominence in the press (e.g. the Wall Street Journal's quarterly pull-out section), in shareholder reports (e.g. the quarterly mailings to pension-plan participants), and elsewhere.

Since the two models isolate marking activity in different sets of funds - average performers (i.e. near the S\&P) in one case, top performers in the other-it might seem they are easy to distinguish in the data. But the concentration of mutual fund holding in certain equities serves to blur this distinction.

If funds "herd" to certain equities, as is suggested by Lakonishok, Shleifer and Vishny (1992), Grinblatt, Titman and Wermers (1995) and Karceski (1999), and a few determined fund managers mark up some of these securities, then other funds will benefit from the marking effect of these managers. Those responsible may not even manage mutual funds; calendar-year and quarter returns are also important in other institutionalinvestor categories, such as pension and hedge funds. Pension and hedge fund managers may herd with mutual funds when picking stocks, and then mark the close. So even if only the benchmark-beating hypothesis is correct, funds in general would show at least 
some of the same return seasonality. And the same applies if only the top-performing hedge funds are marking up. So it is not enough to show that the NAVs of some funds go up then down; we also have to test against these alternative passive scenarios.

\section{NAV Inflation at Quarter-Ends}

In this section, we show that equity funds are overpriced at the close of calendar quarters, in the sense that investors who sell at the quarter-end NAV earn abnormally high returns, and those who buy earn abnormally low returns. This is apparent both in the Lipper mutual-fund indices and in our own database of individual equity funds. The Lipper time series are useful in that they are popular references regarding fund performance (e.g., daily in the Wall Street Journal), they extend through July 7, 2000, and they sort funds along dimensions of interest. The results from our own database extend back further and also permit us to refine our tests on the cross section of the funds and of funds' holdings. Since the time period over which this return accrues is only one day, our results are insensitive to our model of equity market equilibrium.

\section{A Tests Using Lipper Mutual Fund Indices}

Lipper produces many equity-fund indices. We use the nine "style" indices that constitute a 3 by 3 sort of the equities concentrated in \{Small-Cap, Mid-Cap, Large-Cap\} by $\{$ Value, Core, Growth\}, and are available daily from July 13, 1992 through the present. These funds allow us to relate our results on NAV-inflation to the welldocumented (e.g. Fama and French (1992)) variation of average equity returns with size 
and book-to-market value. From the return on the Lipper style indices, we subtract the return on the Lipper index of S\&P 500 funds to obtain excess returns.

If NAV's are inflated at quarter- and year-ends, we should observe abnormally high returns on the last day of each quarter and year, and abnormally low returns on the first day. Let $R_{i, t}$ denote the daily excess return of style index $i$ on day $t$, for $t$ from July 14, 1992 (the first return we can calculate) to July 7, 2000 (the last date when we downloaded Lipper data), and run the following OLS indicator-variable regression,

$$
R_{i, t}=b_{i, 0}+b_{i, 1} Y E N D_{t}+b_{i, 2} Y B E G_{t}+b_{i, 3} Q E N D_{t}+b_{i, 4} Q B E G_{t}+b_{i, 5} M_{E N D_{t}}+b_{i, 6} M B E G_{t}+\gamma_{i, t}
$$

where $Y E N D_{t}$ takes the value of 1 when $t$ is the last day of a year, and 0 otherwise. Similarly, $Q E N D_{t}$ and $M E N D_{t}$ are 1 on the last day of a calendar quarter that is not a year end, and the last day of a month that is not a quarter end, respectively. The variables $Y B E G_{t}, Q B E G_{t}$ and $M B E G_{t}$ are defined analogously, except for the first day of the period. We present the fitted coefficients from these nine regressions in Panels A (YEND and $Y B E G), \mathrm{B}(Q E N D$ and $Q B E G)$ and $\mathrm{C}(M E N D$ and $M B E G)$ of Table I.

The results indicate a strong two-day return reversal pattern across month-end, quarter-end, and year-end periods, especially for small-cap and growth funds. The results are strongest for quarter- and year-ends: of the 36 coefficients in Panels A and B, all but one are in the predicted direction, and all but four are statistically significant at the $10 \%$ level. In addition, the magnitudes decrease strongly in market capitalization, and increase moderately from value to growth. Finally, the evidence in Panel C around nonquarter-end month ends is weak. There is a small and generally statistically significant increase on the last day of the month, but almost nothing the next day. 
The magnitudes of these abnormal returns are quite large, especially considering they accrue over just a few days in a year. In Small-Cap Growth funds, the quarterending positive abnormal returns total an average of 435 basis points, and the quarterbeginning negative returns sum to -345 basis points. For our purposes, it is clear that quarter-end prices are inflated in that selling at those prices delivers economic profits, and there is little of this inflation at other month ends. Further, abnormal returns of this size are unlikely to be due to time-variation in risk-required expected returns.

\section{B Tests Using Daily Individual Mutual Fund Returns}

To further analyze period-end abnormal returns, we construct a database of daily returns on 2829 funds using daily price, dividend and dividend reinvestment NAV data from Micropal. Our database consists of diversified open-end equity mutual funds in the Aggressive Growth, Growth and Income, and Long-term Growth categories as defined by Carhart (1997), and it runs from January 2, 1985 to August 29, 1997. There is some survivor bias in the early years of Micropal data. ${ }^{5}$ We calculate total-return time series and also create four equal-weighted fund indices: one for each of the fund categories above, and one for all funds in our sample. For each index we define its excess return as its own return minus that of the S\&P 500 index (not the Lipper index of S\&P 500 funds, as it is not available daily for much of this period). We run the indicator-variable regression (1), described above, and report the results in Panel A of Table II.

\footnotetext{
${ }^{5}$ For example, 0 of the 463 funds with Micropal data for some of 1985 die in 1985, whereas 1 of the 493 similarly-defined funds in the CRSP monthly mutual-fund database with data for some of 1985 dies in 1985. The analogous numbers for 1990 are 29 out of 807 in Micropal and 8 of 700 in CRSP, and for 1995 it is 66 of 2063 in Micropal and 67 of 1979 in CRSP.
} 
These results mirror those from Lipper. Fund prices are significantly inflated at quarter ends, especially year ends, and there is little or no inflation at other month ends. While these tests show that the mean return is higher on quarter ends, one might ask how widespread across funds is this inflation. To address this, we estimate regression (1) again, but replace the dependent variable with the percentage of funds that outperformed the S\&P on that day. We show these results in Panel B of Table II.

We find $80 \%$ of funds beating the S\&P on the last day of the fourth quarter, compared to $37 \%$ beating the S\&P the next day. At the turn of other quarters, $62 \%$ beat the S\&P on the last day, and $40 \%$ the next. In the fund categories, we see the strongest results among aggressive growth funds- $-91 \%$ and $34 \%$ around the year-end, $70 \%$ and $34 \%$ around other quarter-ends - and the weakest among Growth and Income funds. Since Growth and Income is closest to the Value categorization of Lipper, the pattern across fund categories matches that of Table I.

Tables I and II show that equity funds are significantly overvalued at the ends of quarters, especially the fourth, compared to just before and after. We see this in the Lipper indices, in our own database, and in the fraction of funds beating the S\&P 500. The inflation cuts across styles, but it is strongest in funds with a small-cap or growth orientation. It is worth noting that this is not a projection of any previously-reported regularity in equity returns. The quarter-end results are completely novel, and the yearend results are not indicated in the extensive year-end literature. ${ }^{6}$ Further, as discussed

\footnotetext{
6 The closest would probably be Table III of Sias and Starks (1997), which addresses a different frequency (annual), a different category of institutions (all of them), and finds very different numbers. Sias and Starks also conclude that most of the turn-of-the year effect is due to individual investor trading, whereas we find strong evidence of turn-ofthe-year effects due to specific institutions (mutual funds) trading.
} 
above, there are no market microstructure issues surrounding mutual fund NAVs like there are with individual stock prices, making the results all the more meaningful.

The strong evidence of NAV-inflation at the ends of March, June and September rejects exclusively year-end explanations such as tax-loss selling. The scant evidence around the non-quarter month ends also discounts the possibility of monthly explanations such as transfers to retirement accounts. Does it reflect managers marking up their portfolios? The stronger results in small-cap funds support this view, since the closing prices of less-liquid stocks would presumably be easier to influence. If managers are marking up, are they marking up to beat benchmarks, or to make good performances better? The next section runs a series of empirical tests on the cross section of funds to further examine the quarter-end behavior.

\section{Evidence from the Cross Section of Funds}

The first question we address is whether the end-of-quarter positive return is related to the beginning-of-quarter negative return. It does not have to be. There could be one force raising fund returns on the last day of the quarter, and another independent force reducing them the next day. If the return effects are related, they should correlate negatively in the cross section of funds since a relatively more-inflated NAV should both drive up the quarter-end return and drive down the quarter-beginning return. So the empirical question is whether the cross-sectional relation between funds' day $t$ and day $t$ 1 returns is more negative when $t$ is the first day of a quarter. 
We answer the question with a two-stage regression technique. The first stage is a cross sectional regression of funds' day $t$ excess returns on their own day $t$ - 1 excess returns for all days in our sample. The model is

$$
R_{f, t}=b_{0, c, t}+b_{1, c, t} R_{f, t-1}+\gamma_{f, t}
$$

where $R_{f, t}$ is fund $f$ 's excess (of the S\&P 500) day $t$ return, and $f$ indexes all the funds in one of the four categories $c$ : aggressive growth funds, growth and income funds, longterm growth funds, and all funds together. So for each category $c$ we have a time series of 3200 cross sectional slope coefficients $b_{1, c, 1 / 3 / 1985}, b_{1, c, 1 / 4 / 1985}, \ldots b_{1, c, 8 / 29 / 1997}$. In the second-stage regression, we establish whether these slope coefficients are significantly lower when $t$ is the first day of a quarter. The model is

$$
b_{1, c, t}=\lambda_{0, c}+\lambda_{1, c} Y B E G_{t}+\lambda_{2, c} Q B E G_{t}+\lambda_{3, c} M B E G_{t}+\gamma_{c, t}
$$

where $Y B E G, Q B E G$ and $M B E G$ are defined as before. The hypothesis is that $Y B E G$ and $Q B E G$ enter positively. We report the results in Table III.

The second-stage regressions show the predicted effect. Relative performance reverses around quarter ends, with significantly negative coefficients on all four $Q B E G$ and three of the four $Y B E G$ variables. ${ }^{7}$ One lesson is that conditional performance persistence can be very different from unconditional performance persistence, at least at this frequency. For this study the important lesson is that the quarter-end high return and the next-day low return have a common cause in the inflated quarter-end NAV.

\footnotetext{
7 It may be puzzling that the coefficient on QBEG is larger in the allfunds results than in the category results, but this simply reflects the variation of the intensity of the pattern across categories.
} 


\section{A Marking Up to Beat a Benchmark}

The hypothesis that funds mark up to beat benchmarks is analogous to the hypothesis tested in Degeorge et al. (1999) that firms manage earnings to exceed thresholds. In the former case, funds' discretion over calendar-year performance comes from their influence over their holdings' closing prices, and in the latter case, firms' discretion over quarterly earnings-per-share numbers comes from flexible accounting practices, such as the dating of stale-inventory markdowns. But in either case, the discretion allows managers to move performance between periods, nudging it over hurdles it would have failed.

One way to test the benchmark-beating hypothesis is the approach of Degeorge et al. (1999) of referring to the empirical distribution of performance around the benchmarks. The strategy should distort the distribution around the benchmarks by pushing observations from just below the benchmarks to just above. Degeorge et al (1999) show the distribution of earnings-per-share numbers to be distorted around common benchmarks such as analysts' estimates, and zero. There is an extra mass in the empirical distribution at or slightly above the benchmark, compared to slightly below. If funds mark up to beat the S\&P 500 we should find the analogous result in the distribution of calendar-year fund returns: an extra mass at or slightly above the calendar-year total return of the S\&P 500, relative to slightly below.

To execute this test we need the total return of each fund and of the S\&P 500 . Both are complicated by dividend-reinvestment policies. For total fund returns, we use the annual returns from the CRSP mutual fund database which assumes dividend 
reinvestment on payment dates. ${ }^{8}$ The S\&P 500 total return is similarly ambiguous; we use the figures from the SBBI yearbook calculated by Ibbotson Associates, since they appear to be most frequently referenced in annual reports and the financial press. To avoid allowing precision differences to affect our results (SBBI figures use two decimal places, while CRSP uses more), we round off all return figures to one decimal place. ${ }^{9}$ We say a fund tied the S\&P if its rounded-off return matches the S\&P's rounded-off return, and that it beat the S\&P if its rounded-off return is higher.

Our sample includes all full-year returns of aggressive growth, growth and income, and long-term growth funds (excluding index funds) on CRSP from 1985, the beginning of our daily data, through 1998, the end of the CRSP data. This yields 15,541 fund-years. The empirical distribution of the fund returns minus the S\&P 500 is in Figure 1A. The bin corresponding to tying the S\&P 500 is labeled $0.0 \%$, and the bin corresponding to beating the S\&P 500 by $0.1 \%$ is labeled $0.1 \%$. The mode is about onehalf percent below zero, as would be expected from previous mutual fund research.

If there is a benchmark-beating distortion of the distribution, it is small. Over the 14 years, 86 funds fell $0.1 \%$ below the S\&P 500, 81 funds equaled the S\&P 500, and 74 funds landed $0.1 \%$ above. The test statistic of Degeorge et al. (1999) is not significant ${ }^{10}$ for either the change from $-0.1 \%$ to $0.0 \%$ or the change from $0.0 \%$ to $0.1 \%$.

\footnotetext{
8 Some commercial services such as Bloomberg reinvest on ex-dividend dates so their total-return calculations are usually a few basis points different than the returns reported by funds. 
Perhaps it is too much to expect this the Degeorge et al. test to detect S\&P 500gaming, considering other sources of variance in fund and S\&P returns. It may be easier to detect zero-return gaming, i.e. marking up to be positive for the year. Zero is a static target, unlike the S\&P, although the variance of a fund relative to zero is generally larger than its variance relative to an index, which may makes zero a more difficult benchmark.

We test the hypothesis that funds mark up to be positive by repeating the methodology on funds' unadjusted total returns. Figure 1B shows the distribution of the same funds' total returns (rounded to $0.1 \%$ ). Again, any effect is small, as there are 25 funds at $-0.1 \%, 31$ funds at $0.0 \%$, and 34 funds at $0.1 \%$. As before, the Degeorge et al. (1999) test statistic finds the bin-differences to be statistically insignificant. ${ }^{11}$ So we do not find the footprint consistent with marking up to beat benchmarks.

The Del Guercio and Tkac (2000) finding that investors do not reward funds for beating the S\&P 500 matches our finding that funds do not mark up to beat it. That funds moving ahead of the S\&P 500 on the last day outnumber the funds falling behind it is a result of the high-mean distribution, not a cause. ${ }^{12}$

\footnotetext{
11 This is far away from the peak so we are in the case described in section I of the DeGeorge et al. (1999) appendix. Regardless of how big a window we use to calculate the statistic it is not significant. For example, with 6 bins on either side we calculate $\boldsymbol{\vartheta}=0.89$ for the difference between the $-0.1 \% \mathrm{bin}$ and the $0.0 \% \mathrm{bin}$, and $\boldsymbol{\vartheta}=0.54$ for the difference between the $0.0 \%$ bin and the $0.1 \% \mathrm{bin}$. 


\section{B $\quad$ Marking Up to Improve a Good Performance}

The cross sectional prediction of the leaning-for-the-tape model is that the funds with the best year-to-date performance as of the second-to-last day of the year have the greatest NAV-inflation on the last day. That is, we should expect some inflation among funds in general due to herding, but we should see more inflation among the funds that are actively trying to inflate, and this model identifies top performers as the active ones.

We start with a graph. For each of the twelve year-ends with daily data-1985-86 to $1996-97$ - we sort funds by year-to-date return up to the second-to-last day into 5\%wide fractile bins and then calculate the average excess (of the S\&P 500) return on the last day of the year and on the first day of the next year. So for each fractile-bin we have twelve observations of the two days surrounding the turn of the year. We take the average across the twelve year ends and plot the averages as Figure 2A.

The predicted cross-sectional variation is apparent in the relative means. The average year-end rise is $111 \mathrm{bp}$ for the top $5 \%$, compared to the $62 \mathrm{bp}$ average of the other bins, and the average year-beginning drop is $64 \mathrm{bp}$, compared to a $35 \mathrm{bp}$ average across the other bins. To establish the statistical significance of the top-funds/other-funds difference we can deploy the dummy-variable model from Tables I and II, but with the dependent variable replaced by a top-funds minus other-funds long-short portfolio. We can also sort funds into categories, to see if category-relative performance is influential.

For each trading day $t$ from December 31, 1985, to August 29, 1997, we sort funds both within and across categories by performance over the prior 252 trading days ending day $t-1$. The top ten performers are assigned to the winner portfolio, and the rest 
to the loser portfolio. ${ }^{13}$ Daily returns on each portfolio are calculated, and the dependent variable is the winner return minus the loser return. We then regress this winner minus loser return on the quarter- and year-end indicator variables from Tables I and II, and report these results in Panel A of Table IV.

As expected, there is a strong reversal in year-end returns for the top performing funds. The top 10 overall funds outperform other funds by an extra $42 \mathrm{bp}$ on the last day of the year, and underperform these funds by an extra $29 \mathrm{bp}$ on the subsequent day. These results bear out the cross sectional prediction of the leaning-for-the-tape model. Within categories, we find mixed significance, with three of the six p-values registering below $5 \%$. Whether category-relative performance has more or less influence than universerelative performance has not been settled in the flow/performance literature, as Chevalier and Ellison (1997) group growth and growth-and-income funds together in their analysis, and Brown, Harlow and Starks (1996) study only the category of growth-oriented funds. Our results are consistent with universe-relative performance having more influence, though it could also be that investors do not care about the CRSP fund categorization.

The quarter-end results in Panel A of Table IV are weak, but since the dependent variable is trailing 252-day return, this is not surprising. Presumably, investors focus on quarterly returns at quarter ends. We resolve this by estimating the same model, but

\footnotetext{
13 Results are very similar if the winner portfolio is the top 5\% or top $10 \%$ of funds, rather than the top 10 funds. We chose this specification because the number of funds in each category grows significantly over time, so the number of funds in the top n\% grows over time, causing the variance of the winner portfolio to fall over time which makes the test statistics invalid. For example, there are 96 AG funds in 1985 and 576 AG funds in 1996, so the number of funds in the top 5\% goes from 5 to 29 while the number in the bottom 95\% goes from 91 to 547. Fixing the number of funds in the winner portfolio solves this problem, and does not cause a similar problem in the loser portfolio because it has so many funds in it that the additional diversification is trivial.
} 
using the winner minus loser fund returns over the prior 63 days as the dependent variable. We present these results in Panel B of Table IV.

Once again, the cross section of quarterly performance predicts the cross section of quarter-end inflation. The quarter's top ten performers run up an extra $17 \mathrm{bp}$ at the quarter end, and drop an extra $25 \mathrm{bp}$ on the next day. The shape of the cross sectional variation is apparent in Figure 2B, which is the same as Figure 2A except that funds are sorted on quarter-to-date performance up to the second-to-last day, and the quarters represented are the first, second and third calendar quarters only.

We conclude that cross-sectional patterns in equity funds support the leaning-forthe-tape hypothesis. Across funds, we find little relation to lagged returns unconditionally, but a strong negative relation on the first days of quarters, indicating a causal relation between the quarter-end rise and the quarter-beginning fall. We find no evidence for the benchmark-beating hypothesis in the distribution of annual returns. However, we find strong evidence for the leaning-for-the-tape hypothesis in the extra NAV-inflation among the quarter's and calendar year's best performing funds.

The next section approaches marking-up from the other direction by looking directly at equity trading. We first establish that transactions data show the footprint of marking up, and then test whether the equities held by the top equity funds show more marking-up than other stocks.

\section{Evidence from Equity Transactions}

The previous sections offer indirect evidence that fund managers mark up: NAV's shift up and down as if they were marked up, and the NAV's of funds with more 
incentive and ability to mark up shift more. We would like more direct evidence, like audit trails showing the actual trades these mutual funds' managers ordered. Not surprisingly, these audit trails are unavailable, so we extract what we can from two large databases that are available: the Trades-and-Quotes (TAQ) database of NYSE, AMEX and NASDAQ trading, and the CDA database of funds' portfolio holdings.

Three main results emerge. First, we find that equity-price inflation is localized in a short period within the last half-hour before the close. Next, we find that trading activity is considerably more intense in the last half-hour of a quarter than it is in the last half-hour of other days. These patterns are predicted by the leaning-for-the-tape hypothesis, and they are not predicted by any competing models of period-end trading. Finally, tying the marking activity specifically to mutual funds, we find that that equities in the disclosed portfolios of the best recent performers - the funds marking most intensively under our hypothesis - show relatively more price inflation than other equities, even after controlling for equity capitalization and recent return.

\section{A Intraday Patterns in Equity Transaction Prices}

If, as we hypothesize, the equity-fund inflation results from equity trades intended to affect the close, the underlying equity-price inflation should occur near the close. To see if it does, we construct equity-price indices and track them from the close of the quarter's penultimate day through to the close of the close of the next quarter's first day, checking their value shortly before the quarter's close and shortly after the next quarter's open. The empirical question is how much of the up/down price pattern is concentrated in this narrow span of trading. 
We first identify all equities in the TAQ database that traded on the penultimate day, day -2 . From these stocks, we create a value-weighted index (VW), where each stock is weighted by its end-of-November capitalization on CRSP. We also create equalweighted size quintiles using November capitalizations; these are labeled Small, 2, 3, 4, and Large. We use VW to represent broad market indices such as the S\&P 500 and the size-based indices to separate out the effect on smaller stocks, which are easier targets for marking-up. We then calculate the value of each index as of six moments around the turn of the quarter: $4 \mathrm{pm}$ on the day before the last day of the quarter (day -2$), 10 \mathrm{am}, 3: 30 \mathrm{pm}$ and $4 \mathrm{pm}$ on the quarter's last day $(-1)$, and $10 \mathrm{am}$ and $4 \mathrm{pm}$ on the first day of the next quarter $(+1)$. Each constituent equity is valued at its last transaction price as of these moments, whether or not it traded since the previous moment. While this method sometimes uses stale prices, we find it better than the alternatives of conditioning on trades for each date or for all dates.

If marking-up drives the quarter-end inflation, we should find much of the day !1 return in the last half-hour, between 3:30pm and $4 \mathrm{pm}$. To investigate, we calculate the price return of each index over each interval for all six year-ends (1993 through 1998) and all 20 other quarter-ends (March 1993 through June 1999) in the TAQ database, then take the respective averages. Figures 3A (year-end) and 3B (other quarters) show the cumulative returns over these periods.

The intraday price surge, especially in the last half-hour, is apparent in Figure 3A. The size quintiles all show strong price increases after the open of the last day in both the $10 \mathrm{AM}$ to $3: 30 \mathrm{PM}$ interval and the last 30 minutes, whereas the value-weighted index barely moves. It may seem odd that there is not an equivalent reversal the next day, but 
this accords with the tax-loss selling (i.e. selling pressure on losers ends with the year) and window-dressing (i.e. buying pressure on small stocks begins with the year) models long associated with the turn of the year.

The results from other quarter-ends are free from tax distortions, and there we see not only a large last-half-hour surge in the bottom four quintiles, 10 to $50 \mathrm{bp}$ ahead of the market index, but also a similar reversal the next day. To gauge the statistical significance of these results we calculate the last-half-hour portfolio returns on all days, and test whether they are significantly higher at period-ends. For each full-length (9:30AM to 4:00PM) trading day ${ }^{14} t$ from 1993 to 1999 we sort all stocks that traded on $t-1$ into quintiles by their capitalization as of the last month-end before $t$. Then we calculate, as above, the equal-weighted return $r_{q, t}$ of the quintile $q$ stocks and the valueweighted return $v w_{t}$ of all stocks from 3:30PM to 4:00PM of $t$. We run the regression

$$
r_{q, t}=b_{q, 0}+b_{q, 1} v w_{t}+b_{q, 2} Y E N D_{t}+b_{q, 3} Q E N D_{t}+b_{q, 4} M E N D_{t}+\gamma_{q, t}
$$

where YEND, QEND and MEND are defined as before. Results are in Table V.

The economic and statistical significance of the last-minute price run-ups are easily apparent. The smallest quintile surges over $100 \mathrm{bp}$ in the last half-hour of the fourth quarter, and 26bp in the last half-hour of other quarters. The effect declines steadily as we move to larger-cap indices, down to just a few basis points for the largest quintile. These results indicate that the high quarter-end equity returns are not simply a last-day effect, but rather the end-of-the-last-day effect that marking-up would deliver.

14 This excludes both scheduled short days, such as December 31, 1999, and unscheduled short days such as the snow-related closing on January 8,1996 . 


\section{B Intraday Patterns in Equity Transaction Volume}

The timing of equity-price movements supports the view that the equities are being marked-up, and does not support models that aren't specifically focused on the end of the trading day. But do we see the underlying trading pattern that marking-up would deliver? What would that be? One approach to marking-up would be to submit a buy order just before the close, hoping for that trade at the ask to be the day's last. The trade could be any size, maybe just one share. This approach is simple and requires almost no cash, but it carries the risk of a sell order slipping in, and the inflation is limited to the bid/ask spread. If fund managers mark up with this approach, we should see stocks closing closer to the ask than usual at quarter- and year-ends.

Another approach would be to submit many buy orders, hoping to move the market for the stock either by absorbing its short-term liquidity or by influencing other traders about its value. Success does not turn on exactly which transaction is the last, and the potential inflation is greater, but it requires more cash and it risks exposure. Other traders who infer marking-up from the aggressive buys would sense a selling opportunity. This new liquidity would attenuate price impact, implying more trading - both buyer and seller initiated - for a given amount of inflation. Since the price impact would be short term, this extra trading would occur near the close. ${ }^{15}$

To test for the first approach, i.e. test whether stocks close at the ask relatively more at quarter-ends and year-ends, we run a regression where the dependent variable is the fraction of all stocks closing at the ask or higher, and the explanatory variables are

\footnotetext{
15 Yet another tactic is to transact after the close, on an after-hours exchange. But this only affects the NAV if the valuation agent chooses to use such a price. See "The Price is Wrong: Share Prices: AfterHours Share Deals," The Economist, 8/12/2000, for a discussion.
} 
$Y E N D, Q E N D$ and $M E N D$ from above. For each day $t$ of the TAQ data we let $A S K_{t}$ be the fraction of all the stocks that traded in $t$ whose last transactions were at the best ask or higher as of the transaction time. From Harris (1989) we already expect a high value of $A S K$ at month ends; the empirical question is whether it is particularly high for month ends that are also quarter or year ends. We run two regressions, first on YEND, QEND and $M E N D$, and then on YEND, QEND and YEND+QEND+MEND to establish the difference of the year- and quarter-end effects from the month-end effect. In the latter specification, YEND and $Q E N D$ capture the marginal effect of being a year or quarter end, beyond being a month end. The regression results are in Panel A of Table VI.

The regression replicates the Harris (1989) result (in a disjoint sample period) of high closing at month-ends. The quarter-end effect is even larger, but the year-end effect—while significantly positive — is actually slightly smaller. This suggests that the big year- and quarter-end returns of Figures $3 \mathrm{~A}$ and $3 \mathrm{~B}$ result from more than just the direction of the final trade.

To test for the second approach, i.e. test whether transaction volume is relatively high in the last minutes of quarters and years, we run a regression where the dependent variable measures the abnormal trading volume from 3:30PM to 4:00PM. Specifically, we count the number of trades from 3:30PM to 4:00PM for each full-length trading day $t$, which we call $E N D V O L_{t}$, and then define $E N D F R A C_{t}$ to be $E N D V O L_{t}$ divided by the average $E N D V O L$ over the non-month end days in the year around $t$ (i.e. from six months before $t$ to six months after), minus 1 . So for example if $E N D F R A C_{t}=0.25$, then trading in the last half-hour of $t$ was $25 \%$ above normal. We use a period-relative measure of 
excess trading because of the large increase in trading activity from 1993 to $1999 .{ }^{16}$ The explanatory variables are again $Y E N D, Q E N D$ and $M E N D$ in the first regression, and $Y E N D, Q E N D$ and $Y E N D+Q E N D+M E N D$ in the second. The regression results are in Panel B of Table VI.

The regressions find a significantly large amount of extra trading at year ends and quarter ends $-17 \%$ more at year end, $14 \%$ more at other quarter ends — but only an insignificant $2 \%$ more at other month-ends. We can get a sense of the arrival pattern of these extra trades with a graph. For each year-end, quarter-end or month-end trading day $t$ we count the trades in each minute from 9:30 AM to 4:00 PM, inclusive. Then we normalize as above: divide the value for a minute by the average value for that minute in the non-month-end days in the year around $t$, and subtract 1 (again, we throw out shortened days). The resulting measure of excess trading activity is plotted (averaged over 5-minute intervals, to enhance legibility) as Figure 4.

The graph shows a late burst of trading reaching its highest point in the last five minutes. The excess-trading measure rises to $27 \%$ above normal at year-ends, $16 \%$ above normal at quarter-ends, and also $7 \%$ above normal at other month-ends. It is interesting that the year-end also features extra trading in the middle of the day. Some traders may deliberately transact earlier than usual to avoid the New Year's Eve markingup-related price distortions, or to join the office party.

The evidence on equity prices and trades strongly suggests that equities are marked up. An important question that remains is whether mutual-fund managers in particular are involved in this activity. One way to address this question without

${ }^{16}$ The number of trades in the last half-hour increases from around 23,000 in early 1993 to around 200,000 in late 1999. 
observing the actual trades caused by mutual-fund managers is to measure the relative inflation of the equities held by the year's top-performing funds. We can not generally observe a fund's portfolio but we can observe its semiannual or quarterly statutory disclosures in the CDA database (see Wermers (1999) for a description), which we have from 1989 to 1995 . We sort funds by their performance, and then take the constituents of the top-ranked funds' disclosures as our proxy for top-fund stocks. The empirical question is whether they are relatively more inflated than other stocks. To avoid confusion with other potentially important cross-sectional effects, we control for capitalization and recent return before comparing.

The test is a two-stage procedure. The first stage calculates the inflation of topfund stocks at year-end, relative to other stocks with matching capitalization and recent performance, and the second stage generates a test statistic by relating this inflation to its distribution under the null. Because the 1989-95 span of the CDA portfolio data overlaps with the TAQ equity-price data for only three year-ends, this test uses instead the CRSP daily file to measure equity-price movements.

To capture both the initial rise and the subsequent fall caused by marking up, a stock's inflation at the close of year $y$ is taken to be its return on the last day of $y$ minus its return on the next day, i.e. the first day of year $y+1$. A fund is a top fund for year $y$ if it ranks in the top $10 \%$ for the year up to the second-to-last day of $y$. A stock is a top-fund stock for year $y$ if it is in a top fund's last disclosed portfolio for $y$. For each year $y$ from 1989 to 1995 we sort all stocks by second-to-last day capitalization into size quintiles, and by return over the six months ${ }^{17}$ ending with the second-to-last day into performance

\footnotetext{
17 Six months is the standard reference period for tax-loss selling, owing to the structure of the tax code. See, e.g., Reinganum (1983).
} 
quintiles, yielding $5 \times 5=25$ size- and performance-controlled groups of stocks. We sort each group into a long-short zero-cost portfolio: long in the group's top-fund stocks and short in all the others (equal-weighted on both sides). The final step of the first stage is to calculate the inflation of each portfolio: the portfolio's return on the last day of $y$ minus its return on the first day of $y+1$. Let $I N F L_{i, j, y}$ be the inflation of the size-quintile $i$, performance-quintile $j$ portfolio in year $y$ (if there are no top-fund stocks in quintiles $i$ and $j$ for year $y, I N F L_{i, j, y}$ is regarded as missing). Because $I N F L$ is constructed to represent the relative inflation of top-fund stocks, controlling for size and performance, the empirical question is whether INFL is significantly positive.

In the second stage we calculate, for each $i, j$ and $y$, the distribution of $I N F L_{i, j, y}$ under the null by calculating the analogous statistic in all the other weeks of $y$, using the same calendar time. For example, the last trading day of 1993 was a Friday, and the first trading day of 1994 was a Tuesday. So the last-day-of-1993 return was Thursday-Friday, and the first-day-of-1994 return was Friday-Tuesday. For all the other Fridays of 1993 we subtract the Friday-Tuesday return from the Thursday-Friday return (if markets were open on all those days), giving us about fifty observations. ${ }^{18}$ Under the null hypothesis that $I N F L_{i, j, y}$ comes from the same distribution that we observe in the rest of the year, $I N F L_{i, j, y}$ minus the mean of these observations and divided by their standard deviation, which we denote $S T D_{-} I N F L_{i, j, y}$, is approximately standard normal. ${ }^{19}$ Assuming independence across years, $S T D_{-} I N F L_{i, j, y}$ summed over the $n$ years for which it is available and divided by $n^{1 / 2}$ is also approximately standard normal. And finally,

\footnotetext{
${ }^{18}$ Results are very similar if we match trading time instead of calendar time.

${ }_{19}$ The exact distribution is student $t$ with degrees of freedom equal to the number of observations. We use this approximation because the $t$
} 
assuming independence across and within years, $S T D_{-} I N F L_{i, j, y}$ summed across any $n$ combinations of $i, j$ and $y$ and divided by $n^{1 / 2}$ is approximately standard normal.

We run three categories of tests. First, we test for each $i$ and $j$ whether the topfund stocks in size-quintile $i$ and performance-quintile $j$ are relatively more inflated by summing $S T D \_I N F L_{i, j, y}$ across the $n$ years of available data, dividing the result by $n^{1 / 2}$ and comparing the result to the standard normal distribution. Second, we test whether the top-fund stocks in size-quintile $i$ are relatively more inflated by summing over both $j$ and $y$ (and dividing appropriately) and whether the top-fund stocks in performance quintile $j$ are relatively more inflated by summing over $i$ and $y$. Third, we test whether top-fund stocks in general are relatively more inflated by summing over $i, j$ and $y$. In Table VII we report, for each test, the average of INFL, the sum of $S T D_{-} I N F L$ divided by $n^{1 / 2}$ and the p-value for this quantity from the standard normal distribution.

The overall test statistic in the bottom right of Table VII indicates that top-fund stocks are significantly more inflated, controlling for size and recent performance, with a point estimate of $51 \mathrm{bp}$. The size-quintile results in the rightmost column show the most significance in the mid-cap area, whereas the performance-quintile results find significance at both extremes. The larger estimates for losers are intuitive, in the sense that a top fund would intuitively target stocks that its high-performing competitors would be least likely to hold, and these would be losers, not winners. Because we observe this abnormal performance in the specific holdings of top equity mutual funds, the evidence strongly suggests marking up activity by mutual-fund managers. While mutual funds

with around $50 \mathrm{df}$ is very close to standard normal, and because the number of observations changes slightly from one year to the next. 
might not be generating the entire marking up effect, they appear to at least be one of the major contributors to it.

\section{Summary and Conclusion}

The results of this paper relate to a variety of research areas, investor concerns and regulatory issues. We summarize each briefly.

\section{Anvestor Decision-Making}

We provide evidence that equity-fund prices are significantly inflated at the ends of quarters, especially the end of the year. The implied profit opportunity is largeseveral hundred basis points per year for small-stock funds - and transactions costs are zero, so it is tempting to conclude that investors should buy into equity funds on the second-to-last day of each quarter, and sell the next day, thereby capturing the entire inflation as profit with little risk. But, considering the latitude of mutual-fund complexes to deny abusive transactions, this trading rule is not realistic. Alternatively, investors can simply not buy at the end of a quarter, but wait one day and buy at the beginning of the next quarter. This might seem a minor concern-who is investing on New Year's Eve anyway? - but it is potentially serious because month-ends are common investment dates in automated investment plans.

\section{B Principal/Agent Issues in Money Management}

We show that money managers respond to the incentive to move return between periods by marking up their portfolios. This is similar to the observations that money managers respond to the incentive to boost variance (Brown, Harlow and Starks (1996), Chevalier and Ellison (1997)) and to the incentive to disclose lower-risk portfolios 
(Haugen and Lakonishok (1988), Musto $(1997,1999))$. It is noteworthy that the incentive to mark up comes from the same source as the incentive to boost variance, which is the convex relation between net new investment and performance. This relation is more sensitive to the difference between good returns, consistent with the greater evidence of marking-up among the best recent performers, and it is not sensitive to beating the S\&P 500 or zero, consistent with the lack of evidence of marking up for that purpose. While previous studies suggested that portfolio managers window dress their portfolios as a reaction to either implicit or explicit incentive compensation contracts, our evidence indicates that some funds actively manipulate prices of stocks they hold, which is a completely different ball game.

\section{Regulation}

Marking-up by mutual-fund managers is considered illegal. Should more be done to stop it? Several considerations are important. For one thing, the aggregate monetary effect of marking-up across a fund's investors is zero. That is, all profits to or losses from these investors selling or buying at inflated prices are borne by existing or remaining investors. Of course, one group of investors does systematically lose to another. For example, investors automatically contributing at month-ends will systematically lose to those investing the next day.

Even if nobody transacts at the funds' inflated prices, there is still the issue of the inflated returns overstating the fund's performance for the year, potentially misleading investors. ${ }^{20}$ One possible regulatory solution is to require full disclosure of trades executed on the last day of calendar quarters. But considering how little information past

20 As Moskowitz (2000) observes, our results can explain why funds' stock picks do so much better in December than in any other month. 
performance imparts about future performance, this is not a first-order concern. Also, the elimination of marking-up by mutual-fund managers would not solve all the problems related to marking up if other institutional money managers such as hedge-fund managers continue to mark up. If they mark up the stocks held by a mutual fund that does not mark up, that fund will experience the consequences of price-inflation anyhow.

Regulatory response to marking-up appears to be more active in Canada. The Ontario Securities Commission collected a C\$75,000 settlement from Altamira, a fund management company, with respect to allegations of marking up in 1993 and $1994 .^{21}$ And just recently it collected a C\$3.08 million settlement from RT Capital Management, which admitted month-end and quarter-end marking-up (called "high closing" in Canada) between October 1998 and March 1999. ${ }^{22}$ In the later investigation, fund managers were suspected of using outside accounts for marking-up trades, in which case the trading activity of their funds would reveal no evidence of wrongdoing. ${ }^{23}$

\section{Turn-of-the-year Returns}

The two explanations for the out-performance of small stocks in early January are tax-loss selling and window dressing. These models do not predict the big returns observed in small stocks on the last day of the year, especially in the final moments of the trading day. In contrast, our model predicts these big returns, as well as their concentration in the last minutes of the year and a coincident burst of trading activity. Further, our model predicts the same effects at other quarter ends, which we observe. One interpretation of our results is that the tax-loss selling and window-dressing effects

\footnotetext{
21 "Market Manipulation: Part 3. An exclusive investigation into the 'juicing' of stock prices." The Globe and Mail, July 5, 2000, page B1. 
in small stocks just after the year end would be even larger had small stock prices not been artificially raised at year end.

\section{E. Market Microstructure}

The usual perspective on an investor purchasing a security is that he wants the lowest price and the least impact. The extra trading volume and price movement we document suggests contradictory preferences at work at quarter and year ends. Consequently, research that lumps quarter-end trading with trading in normal circumstances could mismeasure the execution quality and market impact that institutional investors can expect in normal circumstances. The direction of the mismeasurement is an interesting question, similar to the one addressed by Kyle (1985); it may be especially hard to move the market when other traders expect marking-up, so that the market impact of a given purchase is actually smaller. 


\section{References}

Ariel, Robert A., 1987, A monthly effect in stock returns, Journal of Financial Economics 18, 161-174.

Boudoukh, Jacob, Matthew P. Richardson, Marti Subrahmanyam, and Robert F. Whitelaw, 2000, The last great arbitrage: Exploiting the buy-and-hold mutual fund investor, New York University working paper.

Brown, Keith C., W.V. Harlow, and Laura T. Starks, 1996, Of tournaments and temptations: An analysis of managerial incentives in the mutual fund industry, Journal of Finance 51, 85-110.

Brown, Stephen J., and William N. Goetzmann, 1995, Performance persistence, Journal of Finance 50, 679-698.

Carhart, Mark M, 1997, On persistence in mutual fund performance, Journal of Finance 52, 83-110.

Chalmers, John M. R., Roger M. Edelen, and Gregory B. Kadlec, 2000, The wildcard option in transacting mutual-fund shares, Wharton Financial Institutions Center Working Paper 00-03.

Chevalier, Judith, and Glenn Ellison, 1997, Risk taking by mutual funds as a response to incentives, Journal of Political Economy 105, 1167-1200.

Degeorge, François, Jayendu Patel and Richard Zeckhauser, 1999, Earnings management to exceed thresholds, Journal of Business, 72, 1-33.

Del Guercio, Diane, and Paula A. Tkac, 2000, The determinants of the flow of funds of managed portfolios: mutual funds versus pension funds, University of Oregon and Atlanta Fed Working Paper.

Fama, Eugene, and Kenneth French, 1992, The cross-section of expected stock returns, Journal of Finance 47, 427-466.

Givoly, Dan, and Arie Ovadia, 1983, Year-end induced sales and stock market seasonality, Journal of Finance 38, 171-185.

Goetzmann, William N., Zoran Ivkovich and K. Geert Rouwenhorst, 2000, Day trading international funds: Evidence and policy solutions, Yale International Center for Finance Working Paper.

Greene, J.T., and C. W. Hodges, 2000, The dilution impact of daily fund flows on openend mutual funds, Georgia State University Working Paper. 
Grinblatt, Mark, Sheridan Titman, and Russ Wermers, 1995, Momentum investment strategies, portfolio performance, and herding: A study of mutual fund behavior, American Economic Review 85, 1088-1105.

Harris, Lawrence, 1989, A day-end transaction price anomaly, Journal of Financial and Quantitative Analysis, 24, 29-45.

Harris, Lawrence, and Eitan Gurel, 1986, Price and volume effects associated with changes in the S\&P 500 list: New evidence for the existence of price pressures, Journal of Finance, 41, 815-829.

Haugen, Robert, and Josef Lakonishok, 1988, The Incredible January Effect: The Stock Market's Unsolved Mystery (Dow-Jones-Irwin, Homewood Ill.).

Hendricks, Daryll, Jayendu Patel, and Richard Zeckhauser, 1993, Hot hands in mutual funds: Short-run persistence of performance, 1974-88, Journal of Finance 48, 93-130.

Ippolito, Roger A., 1992, Consumer reaction to measures of poor quality: Evidence from the mutual fund industry, Journal of Law and Economics 35, 45-70.

Jegadeesh, Narasimham, and Sheridan Titman, 1993, Returns to buying winners and selling losers: Implications for stock market efficiency, Journal of Finance 48, 65-91.

Karceski, Jason, 1999, An agency explanation for the book-to-market effect, University of Florida working paper.

Keim, Donald, 1983, Size-related anomalies and stock return seasonality: Further empirical evidence, Journal of Financial Economics 12, 13-32.

Kyle, Albert S., 1985, Continuous auctions and insider trading, Econometrica 53, 13151335.

Lakonishok, Josef, Andrei Shleifer and Robert W. Vishny, 1992, The impact of institutional trading on stock prices, Journal of Financial Economics 32, 23-43.

Lakonishok, Josef, Andrei Shleifer, Richard Thaler, and Robert Vishny, 1991, Window dressing by pension fund managers, AEA Papers and Proceedings 227-231.

Lynch, Anthony W., and Richard R. Mendenhall, 1997, New evidence on stock price effects associated with changes in the S\&P 500 index, Journal of Business 70, 351-384.

Moskowitz, Tobias J., 2000, Discussion, Journal of Finance 55, 1695-1703.

Musto, David, 1997, Portfolio disclosures and year-end price shifts, Journal of Finance $52,1563-1588$. 
Musto, David, 1999, Investment decisions depend on portfolio disclosures, Journal of Finance 54, 935-952.

Reed, Adam V, 2000, The life cycle of an arbitrage opportunity: Reconstitutions of the Russell 2000, University of Pennsylvania Working Paper.

Reinganum, Marc, 1983, The anomalous stock market behavior of small firms in January: Empirical tests for tax-loss selling effects, Journal of Financial Economics 12, 89-104.

Ritter, Jay, 1988, The buying and selling behavior of individual investors at the turn of the year, Journal of Finance 43, 701-717.

Roll, Richard W, 1983, Vas ist das? The turn of the year effect and the return premium of small firms, Journal of Portfolio Management 9, 18-28.

Sias, Richard W., and Laura T. Starks, 1997, Institutions and individuals at the turn-ofthe-year, Journal of Finance 52, 1543-1562.

Sirri, Erik R., and Peter Tufano, 1998, Costly search and mutual fund flows, Journal of Finance 53, 1589-1622.

Wermers, Russ, 1999, Mutual fund herding and the impact on stock prices, Journal of Finance 54, 581-622.

Zweig, Jason, 1997, Watch out for the year-end fund flimflam, Money Magazine, November, 130-133. 


\section{Table I}

Excess Returns of the Lipper Mutual-Fund Indices around Period-Ends Model is

$$
X_{t}=\mathrm{b}_{0}+\mathrm{b}_{1} Y E N D_{t}+\mathrm{b}_{2} Y B E G_{t}+\mathrm{b}_{3} Q E N D_{t}+\mathrm{b}_{4} Q B E G_{t}+\mathrm{b}_{5} M E N D_{t}+\mathrm{b}_{6} M B E G_{t}+\varepsilon_{\mathrm{t}}
$$

Nine of the Lipper mutual-fund total-return indices are a 3 by 3 sort of equity funds, \{Small-Cap, Mid-Cap, Large-Cap $\}$ by \{Value, Core, Growth\}. There is also an index of S\&P 500 funds. Daily index levels begin July 13, 1992 and run through July 7, 2000, a total of 2019 trading days. For each of the nine indices we calculate its daily return net of the S\&P-fund index and then regress this excess return on six 1/0 indicator variables: YEND (last trading day of the year), YBEG (first of the year), QEND (last of a calendar quarter other than the fourth), $Q B E G$ (first of a calendar quarter other than the first), MEND (last of a month but not the last of a quarter), and $M B E G$ (first of a month but not the first of a quarter). The coefficients are arranged into panels: YEND/YBEG in Panel A, QEND/QBEG in Panel B, and $M E N D / M B E G$ in Panel C. Results are in basis points. Each regression has 2018 observations.

Panel A: Turn of the Year, YEND/YBEG

$\begin{array}{llll} & \text { Small-Cap } & \text { Mid-Cap } & \text { Large-Cap } \\ \text { Value } & 141^{* *} /-30 & 120^{* *} /-34^{* *} & 25^{* *} /-17^{* * *} \\ \text { Core } & 153^{* *} /-53^{* *} & 155^{* *} /-73^{* *} & 30^{* *} /-20^{* *} \\ \text { Growth } & 174^{* *} /-96^{* *} & 157^{* *} /-78^{* *} & 37^{* *} /-33^{* *}\end{array}$

Panel B: Turn of Calendar Quarters other than Fourth, QEND/QBEG

\begin{tabular}{llll} 
& Small-Cap & Mid-Cap & Large-Cap \\
\cline { 2 - 4 } Value & $59^{* *} /-33^{* *}$ & $31^{* *} /-14$ & $44^{* *} 5$ \\
Core & $71^{* *} /-52^{* *}$ & $60^{* *} /-55^{* *}$ & $8^{* *} /-5^{*}$ \\
Growth & $87^{* *} /-83^{* *}$ & $69^{* *} /-82^{* *}$ & $15^{*} /-17^{* *}$
\end{tabular}

Panel C: Turn of Months other than Quarter-Ends, MEND/MBEG

\begin{tabular}{llll} 
& Small-Cap & Mid-Cap & Large-Cap \\
\cline { 2 - 4 } Value & $25^{* *} /-9$ & $10^{* *} / 12$ & $6^{* *} /-2$ \\
Core & $21^{* *} /-2$ & $25^{* *} /-1$ & $4^{* *} /-1$ \\
Growth & $28^{* *} / 6$ & $26^{* *} / 6$ & $4 / 4$
\end{tabular}

*Significantly Different from Zero at $10 \%$ Rejection Level

${ }^{* *}$ Significantly Different from Zero at 5\% Rejection Level 
Table II

Month-End Mutual-Fund Price Shifts

Model is

$$
X_{t}=\mathrm{b}_{0}+\mathrm{b}_{1} Y E N D_{t}+\mathrm{b}_{2} Y B E G_{t}+\mathrm{b}_{3} Q E N D_{t}+\mathrm{b}_{4} Q B E G_{t}+\mathrm{b}_{5} M E N D_{t}+\mathrm{b}_{6} M B E G_{t}+\varepsilon_{\mathrm{t}}
$$

In Panel $\mathrm{A}$, the dependent variable in each regression is an equal-weighted index of funds, first the Aggressive Growth (AG), Growth and Income (GI) and Long-Term Growth (LG) categories together, and then separately. In Panel $\mathrm{B}$, the dependent variable is the fraction of funds in the indicated universe that beat the S\&P 500 for that day. YEND $t$ is 1 if $t$ is the last trading day of December, $Y B E G_{t}$ is 1 if $Y E N D_{t-I}$ is $1, Q E N D_{t}$ is 1 if $t$ is the last trading day of March, June or September, and $Q B E G_{t}$ is 1 if $Q E N D_{t-1}$ is 1 , $M E N D_{t}$ is 1 if $t$ is the last day of January, February, April, May, July, August, October or November, and $M B E G_{t}$ is 1 if $M E N D_{t-1}$ is 1 . Panel A is in basis points, Panel B is in percentage points, and two-sided pvalues for the null hypothesis of a zero coefficient are below in italics, reported as percentages. Each regression has 3201 observations, covering January 3, 1985 through August 29, 1997.

\begin{tabular}{llllllll} 
Panel A: & \multicolumn{7}{c}{ Dependent Variable is Index Return } \\
\hline$X$ & $\mathrm{~b}_{0}$ & $\mathrm{~b}_{1}$ & $\mathrm{~b}_{2}$ & $\mathrm{~b}_{3}$ & $\mathrm{~b}_{4}$ & $\mathrm{~b}_{5}$ & $\mathrm{~b}_{6}$ \\
\hline All & -0.28 & 53.01 & -25.35 & 16.27 & -11.76 & 1.74 & 6.91 \\
& 68.23 & 0.01 & 1.37 & 0.71 & 5.15 & 63.97 & 6.49 \\
& & & & & & & \\
Aggressive & -0.67 & 95.38 & -38.18 & 34.61 & -21.25 & 8.60 & 10.65 \\
Growth only & 50.60 & 0.01 & 1.14 & 0.01 & 1.66 & 11.57 & 5.26 \\
& & & & & & & \\
Growth and & -0.06 & 22.29 & -12.97 & 5.35 & -6.25 & -3.25 & 4.53 \\
Income only & 91.10 & 0.92 & 11.50 & 26.79 & 19.6 & 27.51 & 13.02 \\
& & & & & & & \\
Long-Term & -0.16 & 47.08 & -25.35 & 12.02 & -9.34 & 0.79 & 6.22 \\
Growth only & 80.02 & 0.01 & 0.82 & 3.28 & 9.71 & 82.02 & 7.48 \\
\hline
\end{tabular}

Panel B: $\quad$ Dependent Variable is \% of funds above $S \& P 500$

\begin{tabular}{llllllll}
\hline$X$ & $\mathrm{~b}_{0}$ & $\mathrm{~b}_{1}$ & $\mathrm{~b}_{2}$ & $\mathrm{~b}_{3}$ & $\mathrm{~b}_{4}$ & $\mathrm{~b}_{5}$ & $\mathrm{~b}_{6}$ \\
\hline All & & & & & & & \\
& 50.52 & 29.60 & -13.15 & 11.54 & -10.19 & 1.85 & 7.00 \\
AG only & 0.01 & 0.01 & 6.50 & 0.59 & 1.49 & 47.49 & 0.70 \\
& & & & & & & \\
& 50.55 & 40.00 & -16.68 & 19.67 & -16.22 & 6.68 & 7.50 \\
GI only & 0.01 & 0.01 & 4.70 & 0.01 & 0.10 & 2.81 & 1.42 \\
& & & & & & & \\
& 50.64 & 19.85 & -6.85 & 5.15 & -5.71 & -1.98 & 6.97 \\
LG only & 0.01 & 0.61 & 32.50 & 20.71 & 16.27 & 43.21 & 0.59 \\
& & & & & & & \\
& 50.41 & 29.93 & -15.00 & 10.77 & -9.27 & 1.41 & 6.80 \\
& 0.01 & 0.01 & 3.63 & 1.05 & 2.75 & 58.72 & 0.91 \\
\hline
\end{tabular}


Table III

\section{Daily Cross Sectional Regressions on Lagged Returns}

$R_{f, t}$ is the return of fund $f$ on day $t$ from January 2, 1985 to August 29, 1997. There are four categories $c$ of funds: Aggressive Growth (AG), Growth and Income (GI), Long-Term Capital Gains (LG), and all funds put together (ALL). For each $t$ from January 3, 1985 through August 29, 1997 and for each $c$ we run a cross-sectional regression $R_{f, t}=b_{0, c, t}+b_{l, c, t} R_{f, t-1}+\gamma_{f, t}$ of the day $t$ returns of the funds in category $c$ on their own day $t-1$ returns, saving the fitted slope coefficient $b_{l, c, t}$. Then for each $c$ we run a second-stage regression of the time series $b_{1, c, 1 / 3 / 1985}, b_{1, c, 1 / 4 / 1985}, \ldots b_{1, c, 8 / 29 / 1997}$ on three dummy variables: $Y B E G_{t}$, which is 1 if $t-1$ is the last trading day of December, $Q B E G_{t}$, which is 1 if $t-1$ is the last trading day of March, June or September, and $M B E G_{t}$, which is 1 if $t-1$ is the last trading day of any other month: $b_{1, c, t}=8_{0, c}+$ $8_{1, c} Y B E G_{t}+8_{2, c} Q B E G_{t}+8_{3, c} M B E G_{t}+\gamma_{c, t}$ Two-sided p-values for the null hypothesis of a zero coefficient are below, in italics, reported as percentages. Each second-stage regression has 3200 observations.

\begin{tabular}{lllll}
\hline & 0 & 1 & \multicolumn{1}{c}{2} & \multicolumn{1}{c}{3} \\
\hline All & 0.0373 & -0.1970 & -0.1639 & -0.0386 \\
& 0.01 & 1.98 & 0.06 & 19.11 \\
& & & & \\
AG & 0.0489 & -0.1745 & -0.0995 & 0.0106 \\
& 0.01 & 5.41 & 5.16 & 73.76 \\
& & & & \\
GI & -0.0180 & -0.2397 & -0.1481 & -0.0560 \\
& 0.28 & 1.28 & 0.64 & 9.58 \\
& & & & \\
LG & 0.0401 & -0.0878 & -0.1233 & -0.0352 \\
& 0.01 & 31.49 & 1.24 & 24.9 \\
\hline
\end{tabular}




\section{Table IV}

\section{Winner Minus Loser Fund Returns around Month-Ends}

Panel A: There are four categories $c$ of funds: Aggressive Growth (AG), Growth and Income (GI), LongTerm Capital Gains (LG), and all funds put together (ALL). Funds are sorted by total return within category $c$ over the 252 days ending $t-1$. The top 10 are the winner portfolio of funds, and the rest are the loser portfolio, both equal-weighted. The winner return minus the loser return on $t$ is denoted $W M L_{c, t}$. We run the regression

$$
W M L_{c, t}=b_{0}+b_{1} Y E N D_{t}+b_{2} Y B E G_{t}+b_{3} Q E N D_{t}+b_{4} Q B E G_{t}+b_{5} M E N D_{t}+b_{6} M B E G_{t}+\varepsilon_{t}
$$

The independent variables are dummies: $Y E N D_{t}, Q E N D_{t}$ and $M E N D_{t}$ are 1 for $t=$ last trading day of the year, quarter (other than year-end), and month (other than quarter-end), respectively, and $Y B E G_{t}, Q B E G_{t}$ and $M B E G_{t}$ indicate the following days, respectively. Figures are in basis points, and one-sided p-values for whether YEND, QEND and $M E N D$ are significantly positive and for whether $Y B E G, Q B E G$ and $M B E G$ are significantly negative, and two-sided p-values for the intercept, are below in italics (in \%).

Panel B: Same as Panel A except that funds are sorted by total return over the 63 days ending $t-1$.

Panel A: Funds Sorted by Annual Return

\begin{tabular}{|c|c|c|c|c|c|c|c|}
\hline Category & $\mathrm{b}_{0}$ & $Y E N D$ & $Y B E G$ & QEND & $Q B E G$ & $M E N D$ & $M B E G$ \\
\hline \multicolumn{8}{|l|}{ All } \\
\hline & 0.41 & 41.88 & -28.00 & 19.96 & -11.00 & 3.58 & 0.11 \\
\hline & 65.22 & 0.11 & 2.04 & 0.65 & 8.63 & 23.54 & 49.11 \\
\hline \multicolumn{8}{|l|}{ AG only } \\
\hline & 1.37 & 19.64 & -27.50 & 11.15 & 0.64 & 0.23 & -1.60 \\
\hline & 7.63 & 4.44 & 0.86 & 5.03 & 53.75 & 47.77 & 35.35 \\
\hline \multicolumn{8}{|l|}{ GI only } \\
\hline & -0.22 & -4.20 & -2.70 & 0.37 & 2.42 & 0.02 & 1.32 \\
\hline & 66.51 & 70.68 & 36.12 & 46.79 & 70.27 & 49.76 & 67.98 \\
\hline \multicolumn{8}{|l|}{$L G$ only } \\
\hline & 0.21 & 13.90 & -17.20 & 10.11 & -6.20 & 4.87 & -1.40 \\
\hline & 75.51 & 8.58 & 4.57 & 4.54 & 14.86 & 9.33 & 35.65 \\
\hline
\end{tabular}

Panel B: Funds Sorted by Quarterly Return

\begin{tabular}{lcclllll}
\hline Category & $\mathrm{b}_{0}$ & $Y E N D$ & $Y B E G$ & QEND & QBEG & MEND & $M B E G$ \\
\hline All & & & & & & & \\
& 1.15 & -5.26 & -58.03 & 17.25 & -24.56 & 1.03 & -3.25 \\
AG only & 26.14 & 62.96 & 0.05 & 2.73 & 0.31 & 42.59 & 27.95 \\
& 3.33 & -21.63 & -51.39 & 2.33 & -11.13 & -5.82 & -6.00 \\
& 0.02 & 94.12 & 0.01 & 38.25 & 7.70 & 88.65 & 10.73 \\
GI only & & & & & & & \\
& -0.83 & -0.92 & -3.51 & -5.50 & -6.40 & -2.75 & 0.03 \\
& 19.83 & 53.65 & 0.02 & 83.35 & 12.99 & 78.38 & 50.3 \\
LG only & & & & & & & \\
& 0.18 & -4.96 & -31.37 & 6.54 & -15.72 & 2.96 & -4.35 \\
& 82.10 & 65.19 & 0.51 & 18.10 & 1.42 & 25.16 & 16.41 \\
\hline
\end{tabular}




\section{Table V}

\section{Abnormal Equity Returns in the Month's Last 30 Minutes}

For every full-length (i.e. market open from 9:30AM to 4:00PM) trading day $t$ in 1993 through 1999, we sort the stocks independently into capitalization quintiles by capitalization as of the last month-end before $t$. We then discard all stocks that did not trade at least once on day $t-1$. We define the return of a stock in the last 30 minutes of $t$ to be the price return from its last transaction as of 3:30PM of $t$ (this could be as old as the previous day) to its last transaction as of 4:00PM of $t$ (this could be the same transaction). The equalweighted average of these returns for the stocks in capitalization quintile $q$ is $r_{q, t}$. We also calculate a valueweighted average $v w_{t}$ of the returns. So we have 5 time series $r_{q, t}$, and also the time series $v w_{t}$, of last-halfhour portfolio returns. For each of the time series $r_{q, t}$ we run the regression

$$
r_{q, t}=b_{q, 0}+b_{q, 1} v w_{t}+b_{q, 2} Y E N D_{t}+b_{q, 3} Q E N D_{t}+b_{q, 4} M E N D_{t}+\gamma_{q, t}
$$

where $Y E N D_{t}, Q E N D_{t}$ and $M E N D_{t}$ are 1 for $t=$ last trading day of the year, quarter (other than year-end), and month (other than quarter-end), respectively. P-values for significant difference from zero are below, in percent and italics. Each regression has 1750 observations.

\begin{tabular}{|c|c|c|c|c|c|c|}
\hline $\begin{array}{l}\text { Dependent } \\
\text { Variable }\end{array}$ & $\begin{array}{l}b_{q, 0} \\
\text { Int. }\end{array}$ & $\begin{array}{c}b_{q, 1} \\
v w_{t}\end{array}$ & $\begin{array}{l}b_{q, 2} \\
Y E N D_{t}\end{array}$ & $\begin{array}{l}b_{q, 3} \\
Q E N D_{t}\end{array}$ & $\begin{array}{c}\boldsymbol{b}_{q, 4} \\
M E N D_{t}\end{array}$ & $\mathbf{R}^{2}(\%)$ \\
\hline$r_{l, t}(\mathrm{small})$ & $\begin{array}{l}0.0017 \\
<0.01\end{array}$ & $\begin{array}{l}0.156 \\
<0.01\end{array}$ & $\begin{array}{l}0.0112 \\
<0.01\end{array}$ & $\begin{array}{l}0.0026 \\
<0.01\end{array}$ & $\begin{array}{l}0.0022 \\
<0.01\end{array}$ & 22.35 \\
\hline$r_{2, t}$ & $\begin{array}{l}0.0011 \\
<0.01\end{array}$ & $\begin{array}{l}0.204 \\
<0.01\end{array}$ & $\begin{array}{l}0.0061 \\
<0.01\end{array}$ & $\begin{array}{l}0.0029 \\
<0.01\end{array}$ & $\begin{array}{l}0.0014 \\
<0.01\end{array}$ & 31.76 \\
\hline$r_{3, t}$ & $\begin{array}{l}0.0007 \\
<0.01\end{array}$ & $\begin{array}{l}0.279 \\
<0.01\end{array}$ & $\begin{array}{l}0.0043 \\
<0.01\end{array}$ & $\begin{array}{l}0.0024 \\
<0.01\end{array}$ & $\begin{array}{l}0.0013 \\
<0.01\end{array}$ & 37.03 \\
\hline$r_{4, t}$ & $\begin{array}{l}0.0004 \\
<0.01\end{array}$ & $\begin{array}{l}0.352 \\
<0.01\end{array}$ & $\begin{array}{l}0.0034 \\
<0.01\end{array}$ & $\begin{array}{l}0.0016 \\
<0.01\end{array}$ & $\begin{array}{l}0.0009 \\
<0.01\end{array}$ & 46.60 \\
\hline$r_{5, t}(\mathrm{big})$ & $\begin{array}{c}0.0001 \\
<0.01\end{array}$ & $\begin{array}{l}0.643 \\
<0.01\end{array}$ & $\begin{array}{l}0.0014 \\
<0.01\end{array}$ & $\begin{array}{l}0.0006 \\
<0.01\end{array}$ & $\begin{array}{c}0.0002 \\
1.01\end{array}$ & 88.07 \\
\hline
\end{tabular}




\section{Table VI}

Abnormal Equity Trading in the Month's Last 30 Minutes

For every trading day $t$ in 1993 through 1999 we calculate two statistics from the TAQ database of NYSE, AMEX and NASDAQ trading: $A S K_{t}$, the fraction of all the stocks that traded in $t$ whose last trade was at or higher than the concurrent best ask, and $E N D V O L_{t}$, the number of trades from 3:30PM to 4:00PM on $t$. If trading did not begin at 9:30AM and end at 4:00PM on $t, E N D V O L_{t}$ is regarded as missing. From $E N D V O L$ we create a new statistic ENDFRAC to represent the departure of $E N D V O L$ from normal: for trading day $t$, $E N D F R A C_{t}$ is $E N D V O L_{t}$ divided by the average of ENDVOL on non-month-end days in the year around $t$ (i.e. from six months before $t$ to six months after), minus 1 . This variable can be calculated for $t$ from July 6, 1993 through July 1, 1999. For each trading day $t$ we also calculate three indicator variables: $Y E N D_{t}$ is 1 if $t$ is the last trading day of the year, $Q E N D_{t}$ is 1 if $t$ is the last trading day of a quarter other than the fourth, and $M E N D_{t}$ is 1 if $t$ is the last trading day of a month other than a quarter-end. All are 0 otherwise. P-values for significant difference from zero are below, in percentage and italics.

Panel A: Dependent Variable is $A_{S K}$

$$
\begin{aligned}
& A S K_{t}=0.217+0.0178 \text { YEND }_{t}+0.0398 \text { QEND }_{t}+0.0242 \text { MEND }_{t} \quad \mathrm{R}^{2}=4.5 \% \\
& \begin{array}{lllll}
0.01 & 9.60 & 0.01 & 0.01 & \mathrm{~N}=1767
\end{array} \\
& \text { ASK }_{t}=0.217-0.0065 \text { YEND }_{t}+0.0155 \text { QEND }_{t}+0.0242\left(\text { YEND }_{t}+\boldsymbol{Q E N D}_{\boldsymbol{t}}+\boldsymbol{M E N D}_{t}\right) \quad \mathrm{R}^{2}=4.5 \% \\
& \begin{array}{lllll}
0.01 & 56.81 & 3.12 & 0.01 & \mathrm{~N}=1767
\end{array}
\end{aligned}
$$

Panel B: $\quad$ Dependent Variable is ENDFRAC

$$
\begin{aligned}
& \text { ENDFRAC }_{t}=-0.0043+0.1730 \text { YEND }_{t}+0.1440 \text { QEND }_{t}+0.0225 \text { MEND }_{t} \quad \mathrm{R}^{2}=2.4 \% \\
& \begin{array}{lllll}
19.21 & 0.07 & 0.01 & 22.73 & \mathrm{~N}=1499
\end{array} \\
& \text { ENDFRAC }_{t}=-0.0043+0.1504 \text { YEND }_{t}+0.1215 \text { QEND }_{t}+0.0225\left(\text { YEND }_{t}+\text { QEND }_{t}+\text { MEND }_{t}\right) \mathrm{R}^{2}=2.4 \% \\
& \begin{array}{lllll}
19.21 & 0.54 & 0.05 & 22.73 & \mathrm{~N}=1499
\end{array}
\end{aligned}
$$




\section{Table VII}

\section{Year-end overvaluation: winner-fund vs. non-winner-fund stocks}

Each year from 1989 to 1995 stocks are sorted into 5 performance quintiles by six-month return up to the second-to-last day of the year, and 5 size quintiles by capitalization as of the second-to-last day of the year. This yields 25 size/performance groups, and stocks within each group are arranged into a zero-cost portfolio, long in the stocks that were in the most recently (as of December 31 of that year) disclosed portfolio of one of the top $10 \%$ (by performance) equity funds of the year (through the second-to-last day) and short the remaining stocks in this group. For size-quintile $i$ and performance-quintile $j$, the last-day-ofyear- $y$ return minus the first-day-of-year- $y+1$ return is labeled $I N F L_{i, j, y}$. We calculate the same statistic for the same calendar days in every week of year $y$, yielding about 50 observations of analogous returns. We define $S T D_{-} I N F L_{i, j, y}$ as $I N F L_{i, j, y}$ minus the mean of these analogous returns over year $y$ and divided by the standard deviation of the analogous returns over year $y$. In the $6 x 6$ matrix of cells in the table, the cell in row $i$ and column $j, i, j$ from 1 to 5 , shows the average of $I N F L_{i, j, y}$ over the $n$ available yearly observations, and under that the sum of STD_INFL $L_{i, j, y}$ divided by $n^{1 / 2}$ (labeled Stdinfl) and under that, in italics and percent, the p-value from the Standard Normal distribution for the null hypothesis that the true mean is not positive. In the last column, we calculate the average of $I N F L_{i, j, y}$ and sum of $S T D_{-} I N F L_{i, j, y}$ divided by $n^{1 / 2}$ over all the yearly observations across returns groups within each capitalization quintile (i.e., over $y$ and $j$ ). Similarly, in the last row we average and sum across capitalization groups within each return quintile. In the bottom right corner, we report the results from averaging and summing all the yearly observations across both capitalization and returns quintiles, that is, every observation.

\begin{tabular}{|c|c|c|c|c|c|c|}
\hline $\begin{array}{l}\text { Capital- } \\
\text { ization }\end{array}$ & 1 (low) & 2 & $\begin{array}{c}\text { Return } \\
3\end{array}$ & 4 & 5 (high) & all \\
\hline 1(low) & 0.0175 & 0.0630 & -0.0415 & 0.0149 & -0.0227 & 0.0087 \\
\hline stdinfl & 1.424 & 2.629 & -0.482 & 0.286 & -0.483 & 1.635 \\
\hline p-val & 7.73 & 0.43 & 68.52 & 38.73 & 68.54 & 5.11 \\
\hline 2 & 0.0117 & -0.0033 & -0.0139 & 0.0006 & 0.0121 & 0.0016 \\
\hline stdinfl & 1.782 & -0.366 & -1.125 & 0.140 & 0.665 & 0.526 \\
\hline p-val & 3.74 & 64.29 & 86.97 & 44.44 & 25.32 & 29.94 \\
\hline 3 & 0.0114 & 0.0041 & 0.0012 & 0.0101 & 0.0134 & 0.0080 \\
\hline stdinfl & 3.039 & 2.097 & -0.205 & 2.154 & 2.477 & 4.276 \\
\hline p-val & 0.12 & 1.80 & 58.12 & 1.56 & 0.66 & $<0.01$ \\
\hline 4 & 0.0087 & 0.0094 & 0.0081 & 0.0075 & 0.0063 & 0.0080 \\
\hline stdinfl & 1.244 & 3.264 & 3.318 & 2.939 & 2.030 & 5.722 \\
\hline p-val & 10.68 & 0.06 & 0.05 & 0.16 & 2.12 & $<0.01$ \\
\hline 5 (high) & -0.0055 & 0.0013 & -0.0000 & -0.0000 & 0.0023 & -0.0004 \\
\hline stdinfl & -0.722 & 0.483 & -0.227 & 0.204 & 0.607 & 0.154 \\
\hline p-val & 76.48 & 31.47 & 58.98 & 45.59 & 27.18 & 43.86 \\
\hline all & 0.0088 & 0.0120 & -0.0060 & 0.0062 & 0.0035 & 0.0051 \\
\hline stdinfl & 3.026 & 3.546 & 0.703 & 2.720 & 2.489 & 5.608 \\
\hline p-val & 0.12 & 0.02 & 24.09 & 0.33 & 0.64 & $<0.01$ \\
\hline
\end{tabular}




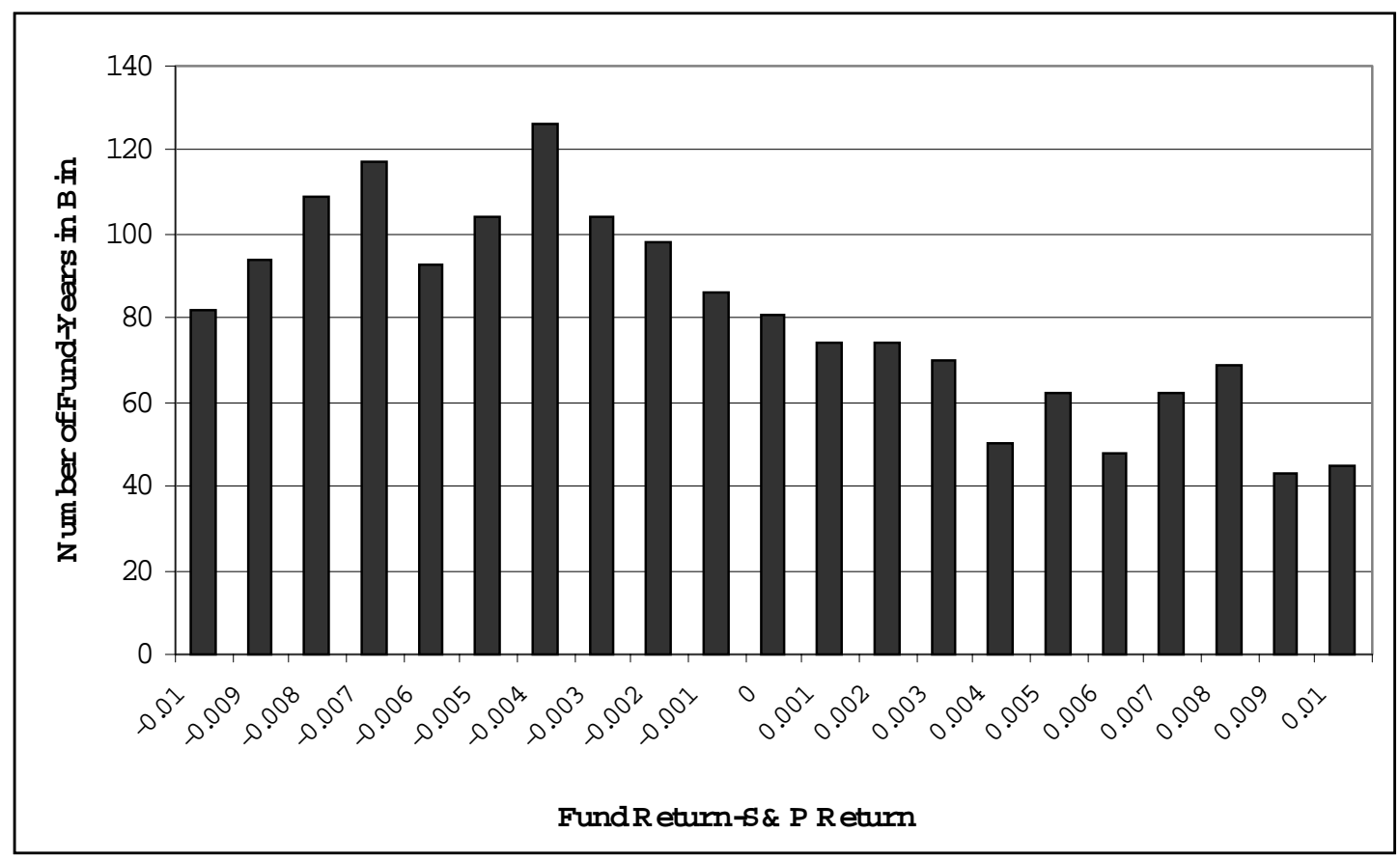

Figure 1A. Distribution of fund calendar-year total returns (rounded off to $0.1 \%$ ) minus S\&P total returns (rounded off to $0.1 \%$ ). All AG, GI and LG funds, 1985-98. Only bins within $1 \%$ of $0 \%$ are represented.

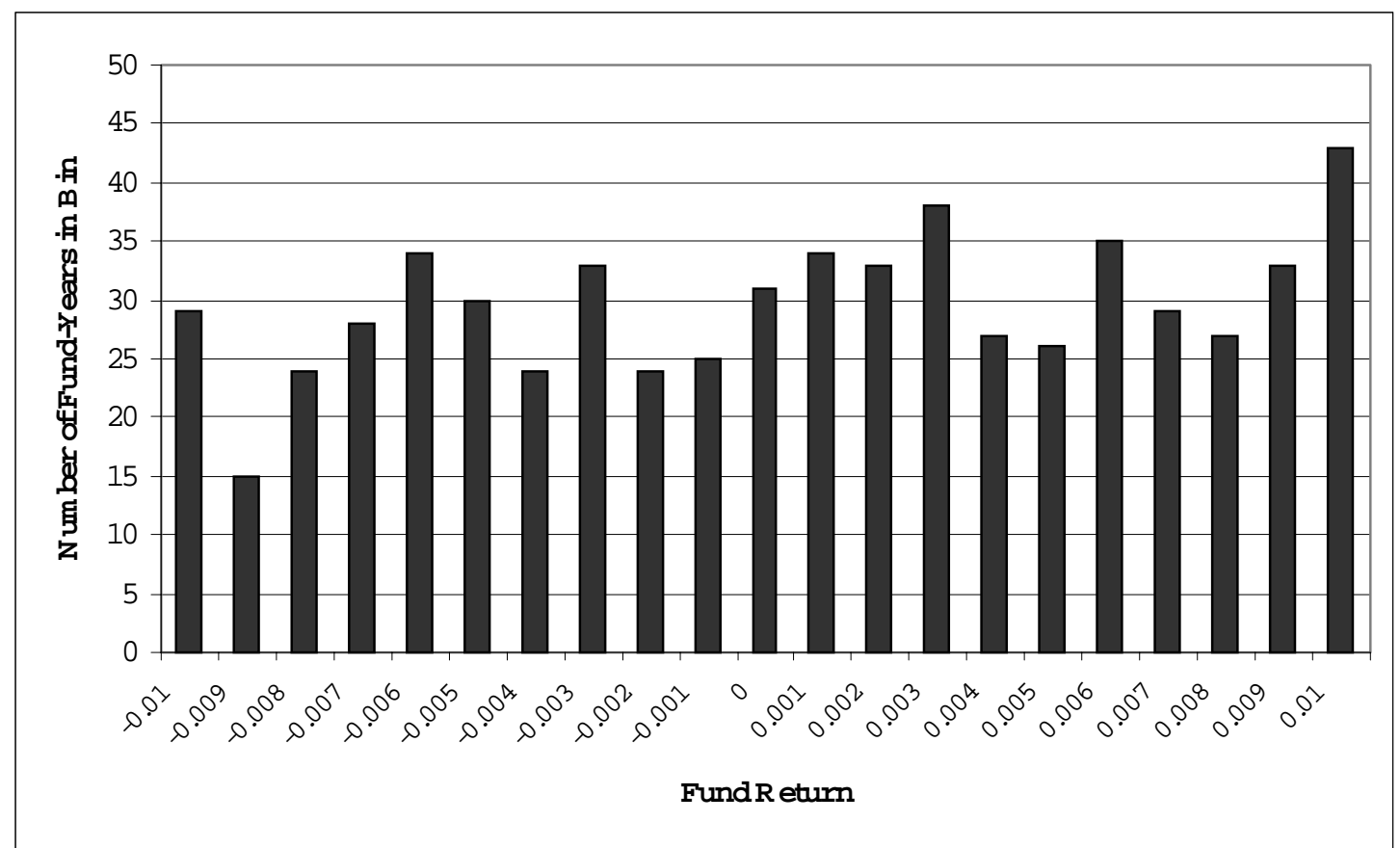

Figure 1B. Distribution of fund calendar-year total returns, rounded off to $0.1 \%$. All AG, GI and LG funds, 1985-98. Only bins within $1 \%$ of $0 \%$ are represented 


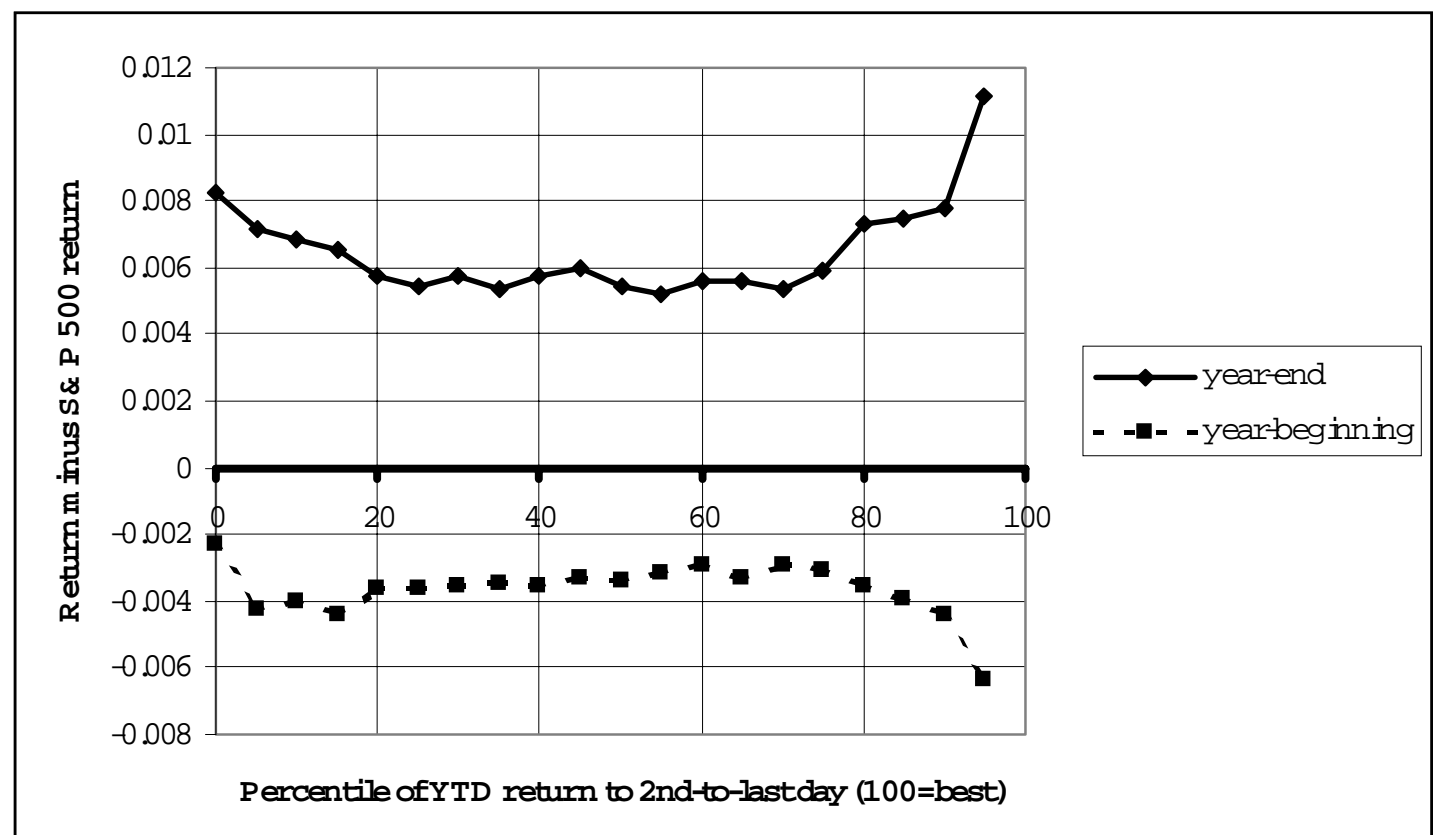

Figure 2A. Funds' average excess (of S\&P) return on the last day of the year ("year-end") and the next day ("year-beginning"), sorted by the percentile of year-to-date return through the second to last day of the year relative to all funds that year.

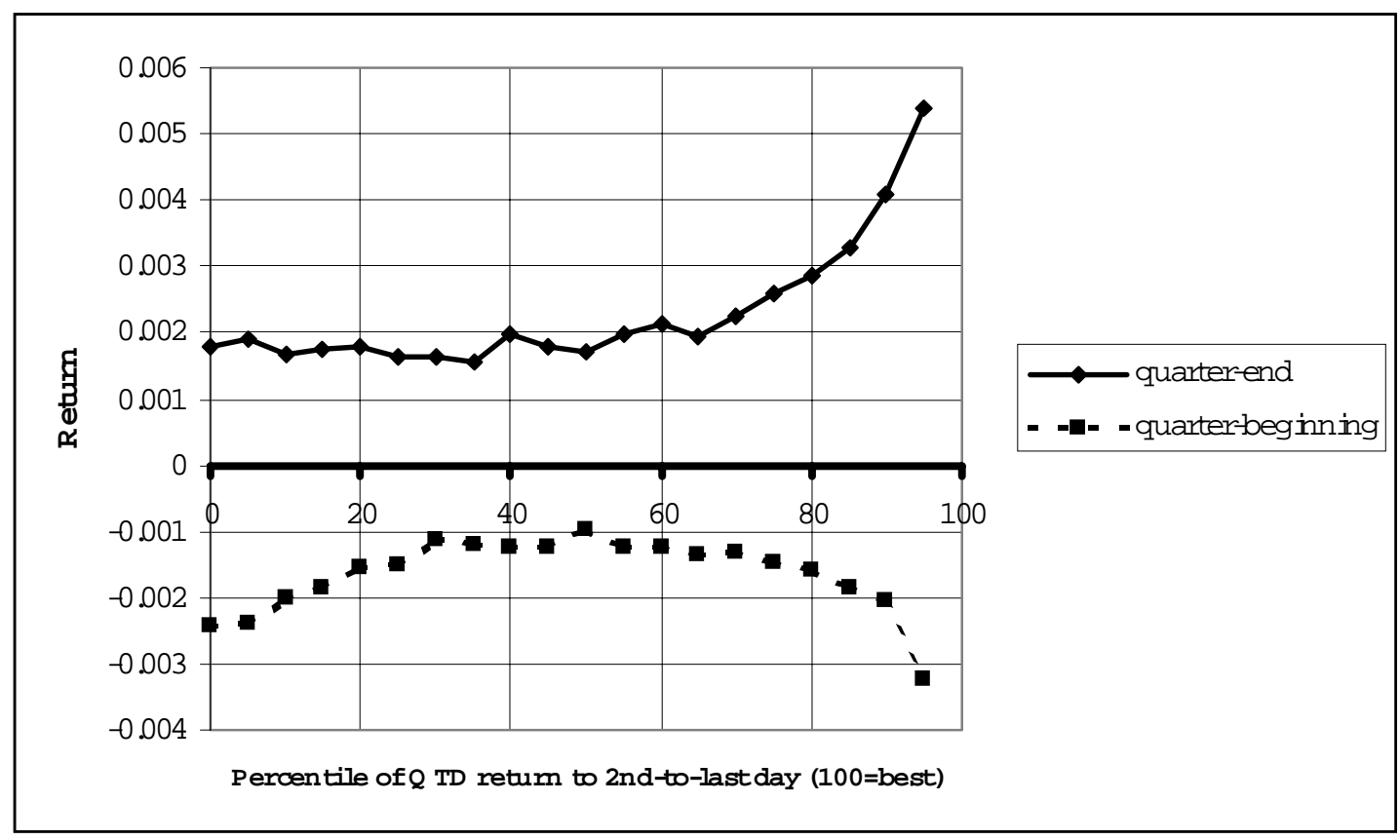

Figure 2B. Funds' average excess (of S\&P) return on the last day of the quarter ("quarter-end") and the next day ("quarter-beginning"), sorted by the percentile of quarter-to-date return through the second to last day of the quarter relative to all funds that quarter. Fourth quarters are excluded. 


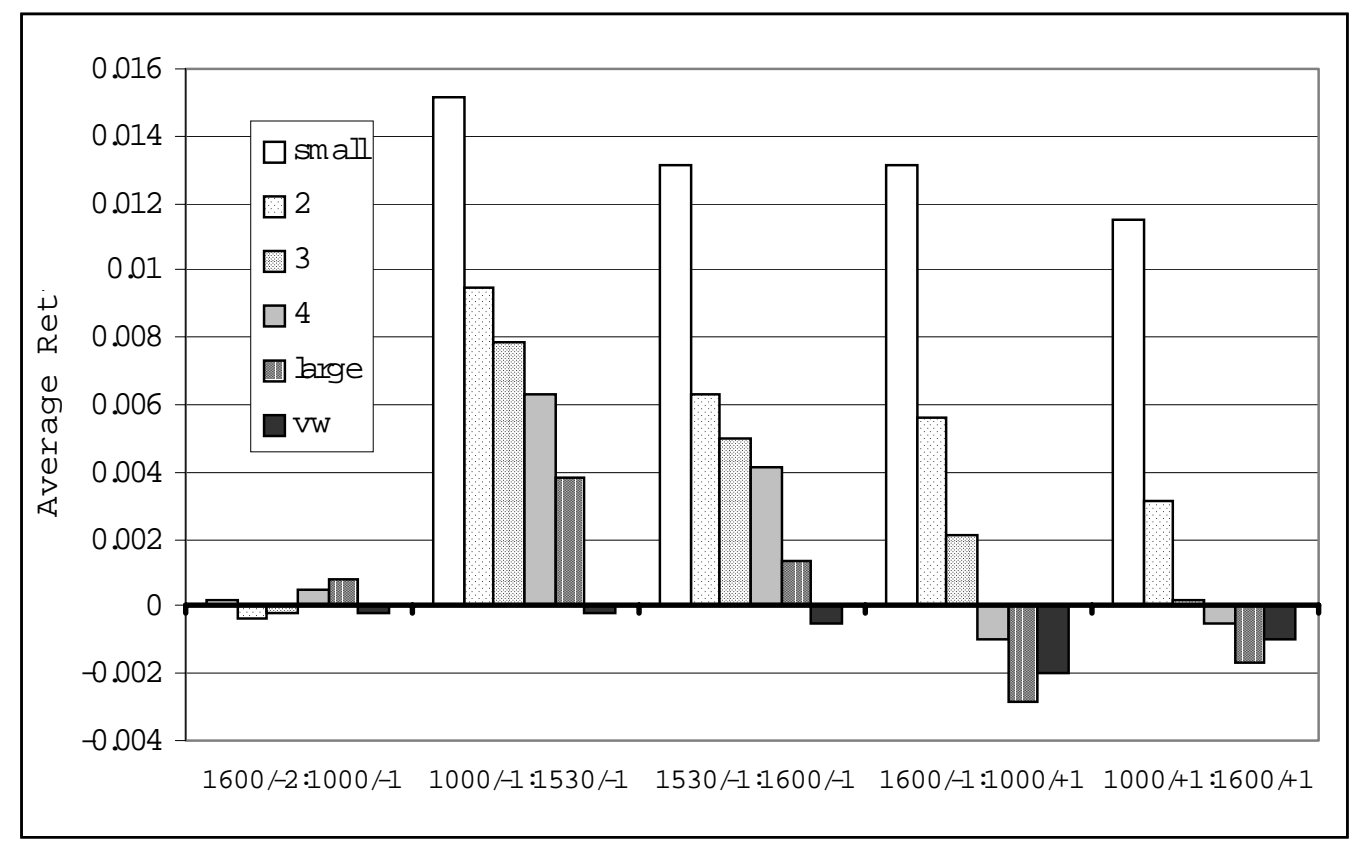

Figure 3A: Intraday Returns around Year-Ends. Average Return of Size Quintiles and the valueweighted index around Year-Ends, 1993 through 1998. Day -1 is the last trading day of the year, day -2 is the day before, and day +1 is the day after. 1600 is the $4 \mathrm{PM}$ close of trading, 1000 is $10 \mathrm{AM}$, and 1530 is 3:30PM.

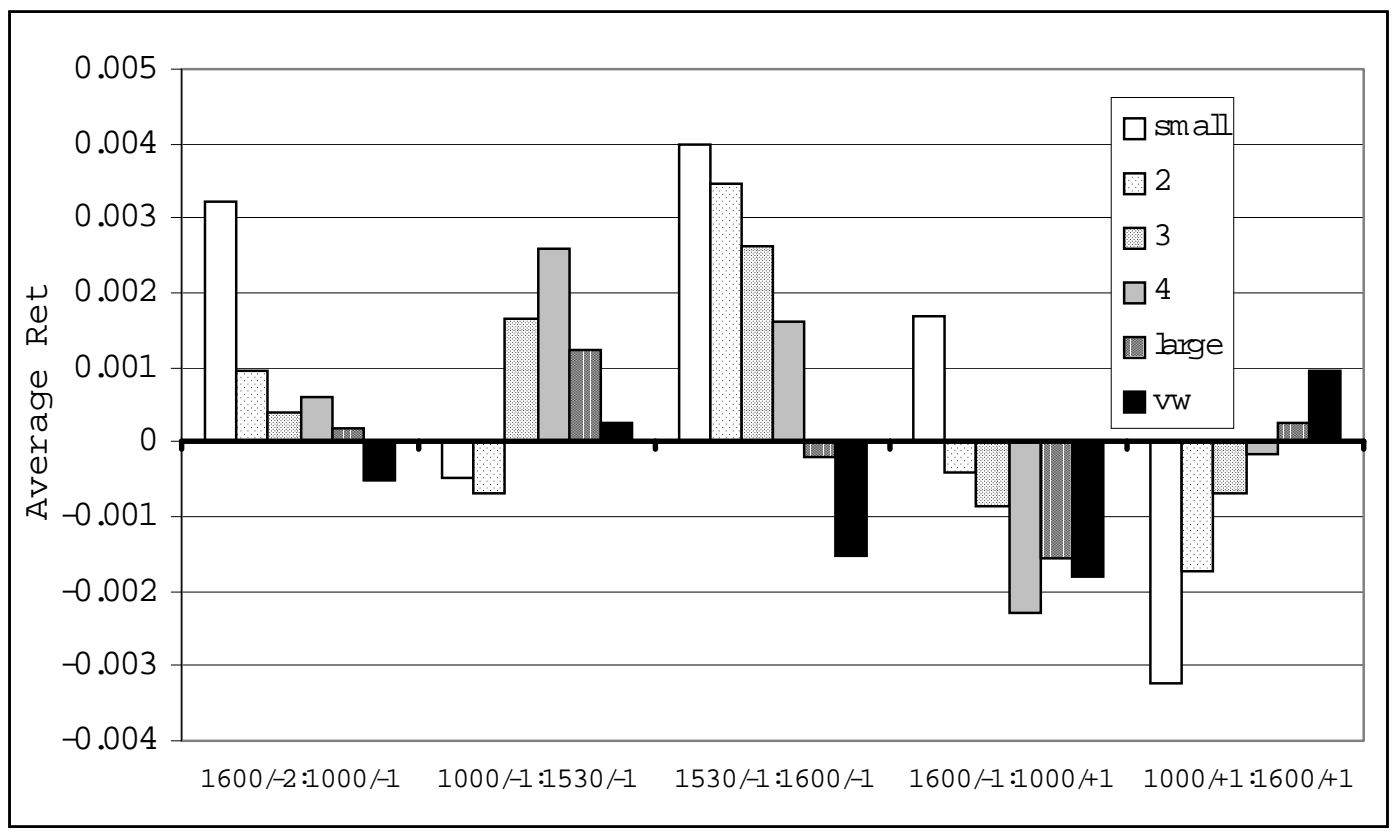

Figure 3B: Intraday Returns around other Quarter-Ends. Average Return of Capitalization Indices around Quarter-Ends other than Year-Ends, 3/1993 through 9/1999. Day -1 is the last trading day of the year, day -2 is the day before, and day +1 is the day after. 1600 is the $4 \mathrm{PM}$ close of trading, 1000 is $10 \mathrm{AM}$, and 1530 is $3: 30 \mathrm{PM}$. 


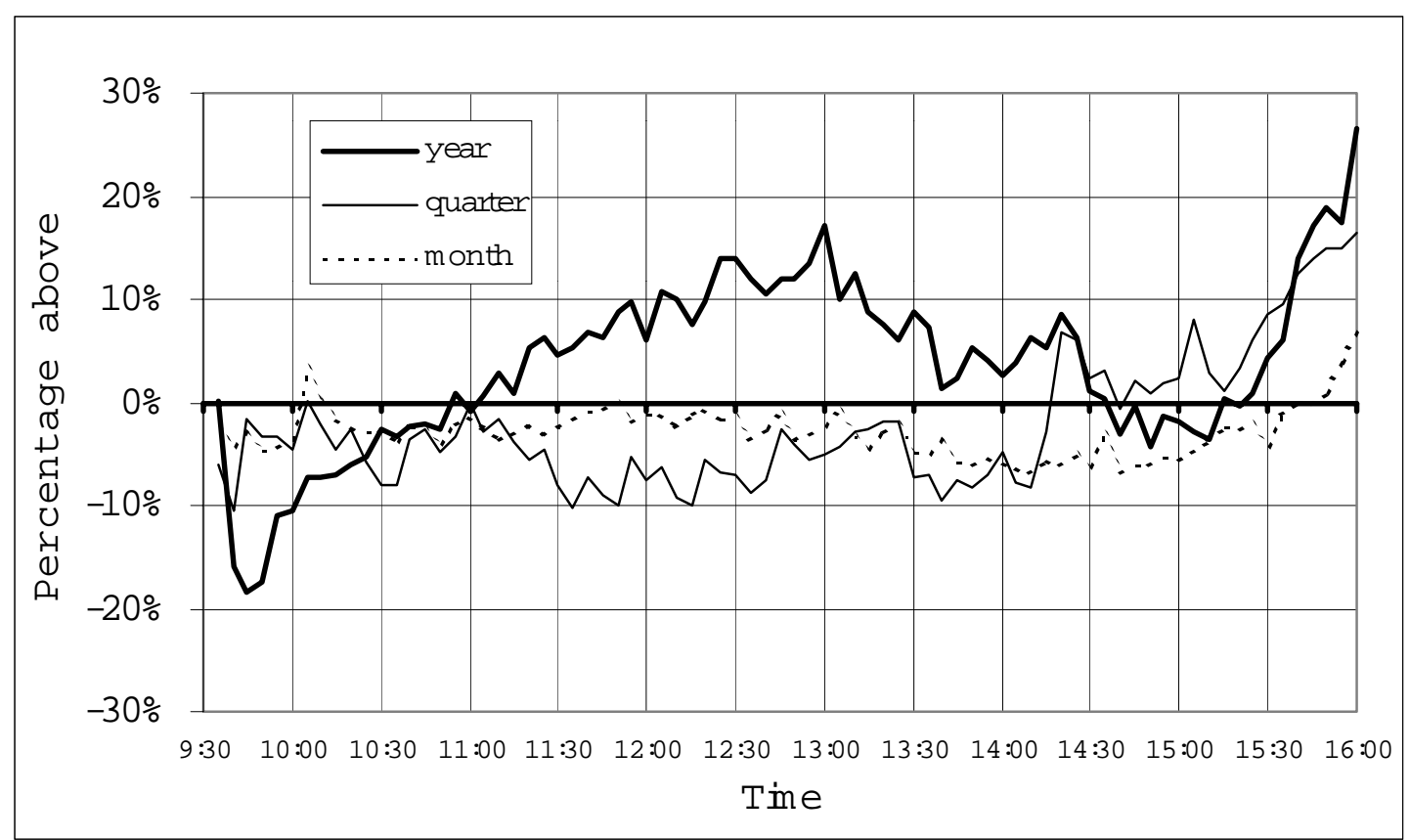

Figure 4. Trading Volume on Period-end days relative to neighboring non-period-end days, July 1993 to June 1999. The "year" line shows the average across the six year ends from 1993 to 1998, the "quarter" line shows the average across the 18 non-year-end quarter-ends from September 1993 to June 1999, and the "month" line shows the average across the 48 non-quarter-end month-ends from July 1993 to May 1999. 